\title{
Pravastatin improves risk factors but not ischaemic tolerance in
}

\section{obese rats.}

Massa Oi ${ }^{1}$, Daniel Donner ${ }^{1}$, Jason Peart ${ }^{1}$, Belinda Beck ${ }^{2}$, Lauren Wendt ${ }^{1}$, John P. Headrick ${ }^{1}$, Eugene F. du Toit ${ }^{1}$.

${ }^{1}$ School of Medical Science, ${ }^{2}$ School of Allied Health Science, Menzies Health Institute Queensland, Griffith University Gold Coast, Southport QLD 4222, Australia.

\section{Corresponding Author:}

Dr. E.F. Du Toit

School of Medical Science

Griffith University

Southport QLD 4222

AUSTRALIA

Ph: (+61) 755529728

Fax: (+61) 755528908

E-mail: j.dutoit@griffith.edu.au 


\section{Abstract}

Statins are effective in management of dyslipidaemia, and a cornerstone of CVD prevention strategies. However, the impacts of their pleiotropic effects on other cardiovascular risk factors and myocardial responses to infarction are not well characterised. We hypothesised that pravastatin treatment in obesity improves lipid profiles, insulin-resistance and myocardial resistance to ischaemia/reperfusion (I/R) injury. Wistar rats were fed a control (C) chow or high carbohydrate and fat diet (HCFD) for 16 weeks with vehicle or pravastatin (prava $7.5 \mathrm{mg} / \mathrm{kg} /$ day) treatment for 8 weeks. At 16 weeks HOMAs were performed, blood samples collected and hearts excised for Langendorff perfusions/biochemical analyses. Antioxidant activity and proteins regulating mitochondrial fission/fusion and apoptosis were assessed. The HCFD increased body weight $(736 \pm 15$ vs. $655 \pm 12 \mathrm{~g}$ for $\mathrm{C} ; \mathrm{P}<0.001)$, serum triglycerides $(2.91 \pm 0.52$ vs. $1.64 \pm 0.26 \mathrm{mmol} / \mathrm{L}$ for $\mathrm{C} ; \mathrm{P}<0.001)$ and insulin-resistance (HOMA- $6.9 \pm 0.8$ vs. $4.2 \pm 0.5$ for $\mathrm{C} ; \mathrm{P}<0.05$ ) while prava prevented diet induced changes and paradoxically increased lipid peroxidation. The HCFD increased infarct size $(34.1 \pm 3.1 \%$ vs. $18.8 \pm 3.0 \%$ of $\mathrm{AAR}$ for $\mathrm{C} ; \mathrm{P}<0.05)$, which was unchanged by prava in $\mathrm{C}$ and $\mathrm{HCFD}$ animals. The HCFD decreased cardiac TxR activity and mitochondrial MFN-1 and increased mitochondrial DRP-1 (reducing MFN-1:DRP-1 ratio) and Bax expression, with the latter changes prevented by prava. While unaltered by diet, cytosolic levels of Bax and caspase-3 were reduced by prava in C and HCFD hearts (without changes in cleaved caspase-3). We conclude that obesity, hyper-triglyceridemia and impaired glycemic control in HCFD rats are countered by prava. Despite improved risk factors, prava did not reduce myocardial infarct size, potentially reflecting its complex pleiotropic impacts on cardiac GPX activity and MFN1, DRP-1, caspase-3 and Bcl-2 proteins.

Keywords: Statins; Ischaemia-reperfusion; Myocardial Infarction; Obesity; Reperfusion Injury; Mitochondrial dynamics. 


\section{ACCEPTED MANUSCRIPT}

\section{Introduction}

The pronounced increase in global incidence of obesity has led to a high prevalence of its comorbidities, which are all major cardiovascular disease (CVD) risk factors. Patients with 3 or more obesity comorbidities (dyslipidaemia, hypertension, insulin-resistance/diabetes) have the metabolic syndrome (MetS) (Eckel et al., 2010), which greatly increases risk of developing coronary artery disease (Kannel et al., 1961), decreases myocardial tolerance to

I/R (Bouhidel et al., 2008; Du Toit et al., 2008; Clark et al., 2011; Wensley et al., 2013) and increases the risk of cardiac death 2-4 fold (Lakka et al., 2002). In this growing population statin therapy is the cornerstone for management of dyslipidaemia and reduction of cardiovascular risk (Gu et al., 2014; O’Keeffe, Nazareth and Petersen, 2016). Although statins are highly effective for the maintenance of normal lipid levels, they also exert complex pleiotropic effects independent of lipid lowering actions (Zhou and Liao, 2009; Allen and Mamotte, 2017). As the single most prescribed cardiovascular drug (Stewart, 2017), it is important to delineate these pleiotropic actions and how chronic statins may modify disease processes in those that ultimately do suffer an ischaemic insult.

We recently showed that myocardial tolerance to $I / R$ in obesity is dependent on the presence or absence of insulin-resistance (Donner et al., 2013). Data suggest that isolated obesity and dyslipidaemia may actually protect the heart whereas obesity with insulin-resistance adversely impacts ischaemic tolerance in a rodent model of MetS (Donner et al., 2013). Cardioprotection with obesity has also been recently reported by others (Salie et al., 2014; Webster et al. 2017). Prolonged untreated dyslipidaemia and elevated circulating nonesterified fatty acids associated with obesity are implicated in the aetiology of insulinresistance and diabetes (Lopaschuk et al., 2007; Chess and Stanley, 2008). However, the efficacy of lipid lowering drugs for the prevention/attenuation of insulin-resistance is 


\section{ACCEPTED MANUSCRIPT}

controversial, with studies suggesting statins can decrease (Bellia et al., 2012; Sato et al., 2012), have no effect (Panz et al., 2012) or improve (Fraloub et al., 2012; Guo et al., 2012) insulin sensitivity in insulin-resistant/diabetic animals and patients. Several studies suggest pravastatin may also improve insulin-resistance in hypercholesterolaemic patients (Koh et al., 2013) and rats (Bełtowski et al., 2011). Improved insulin sensitivity may in turn impact cardiac mitochondrial turnover (Gonzalez-Franquesa and Patti, 2015; Montgomery and Turner. 2015) and apoptosis ( $\mathrm{Li}$ et al., 2017), with insulin-resistance strongly associated with mitochondrial dysfunction (Dumas et al., 2009; Pagel-Langenickel et al., 2010; GonzalezFranquesa and Patti, 2015; Montgomery and Turner. 2015). Statin dependent changes in insulin resistance may therefore influence I/R injury during and after a myocardial infarct.

We hypothesise that pravastatin improves cardiometabolic risk factors (adiposity, lipid profiles, insulin sensitivity) and intrinsic myocardial resistance to I/R injury. In this study we assess the effects of pravastatin treatment in lean and obese rats on: 1) morphometry and body composition; 2) cardiometabolic risk factors; 3) myocardial I/R tolerance; 4) myocardial antioxidant enzyme activity; and 5) myocardial expression of proteins regulating apoptosis and mitochondrial fission and fusion.

\section{Materials and methods}

\subsection{Animal model}

All experiments were conducted in accordance with the NHMRC's Australian code for the care and use of animals for scientific purposes. This project was approved by the Griffith University Animal Ethics committee (MSC/01/14/AEC). Rats were housed in the Griffith University Animal Unit with a 12/12 h light/dark cycle and temperature and humidity set at $21^{\circ} \mathrm{C}$ and $40 \%$ respectively. Sixty male Wistar rats (8 week old) were randomly assigned to 


\section{ACCEPTED MANUSCRIPT}

one of four groups: a control diet fed group (C); a high fat diet (HCFD) fed group; a control diet plus pravastatin (Prava) treated (C+Prava) group; and a HCFD plus pravastatin treated (HCFD+Prava) group. Animals were on the respective diets for 8 weeks before vehicle or pravastatin treatment was commenced for 8 weeks. Pravastatin $(7.5 \mathrm{mg} / \mathrm{kg} /$ day $)$ or vehicle was administered daily via oral gavage. Rats were weighed and pravastatin dosages adjusted weekly to compensate for body weight changes during the 8 week treatment period. Standard rat chow contained $70 \%$ carbohydrates, $23 \%$ proteins and $7 \%$ fat; while the HCFD contained $70 \%$ carbohydrates, $13 \%$ proteins and $17 \%$ fat. All animals were allowed ad libitum access to fresh food and water.

Ten rats from each group were randomly assigned to ex vivo Langendorff perfusion experiments in which cardiac function and myocardial infarct size was assessed. The remaining 5 animals from each group were used for blood and myocardial tissue collection for blood chemistry, ELISA analysis, and myocardial enzyme activity (spectrophotometry) and protein expression (Western blot) analyses.

\subsection{Body weight, body composition and glucose tolerance and lipid profile analyses}

2.2.1. Body weight: Animals were weighed weekly and dual-energy X-ray absorptiometry (DXA) scans and glucose tolerance tests (GTTs) were performed at 8 and 16 weeks to assess effects of diet and pravastatin on body composition and insulin sensitivity.

2.2.2. DXA scans: Animals were anaesthetised with an i.p. injection of $50 \mathrm{mg} / \mathrm{kg}$ ketamine (Ketamil, Troy Laboratories, Australia) and $3 \mathrm{mg} / \mathrm{kg}$ xylazine (Ilium xylazil-20, Troy Labrotories, Australia). DXA scans (XR-36 Quickscan densitometer, Norland Medical 


\section{ACCEPTED MANUSCRIPT}

Systems, Inc., USA) were performed at 8 and 16 weeks, with scans performed at a high resolution $(1.5 \times 1.5 \mathrm{~mm}$, speed of $6 \mathrm{~mm} / \mathrm{s})$ in "small animal mode".

2.2.3. GTTs and lipid profiles: The GTTs were performed 3 days following DXA scanning to allow complete recovery from associated anaesthesia. Lipid profiles were determined using a blood-lipid analyser (L.D.X Cholestech Analyser, Alere ${ }^{\mathrm{TM}}$, Australia). Animals were fasted for $6 \mathrm{~h}$ with only access to water, anaesthetised with iso-fluourene (5\%), and glucose was administered via i.p. injection at a dose of $2 \mathrm{~g} / \mathrm{kg} / \mathrm{body}$ weight. Blood glucose was monitored at 30 min intervals for 2 h (L.D.X Cholestech Analyser, Alere ${ }^{\mathrm{TM}}$, Australia).

\subsection{Heart perfusions for assessing myocardial mechanical function and infarct responses}

Rats were anesthetised (60 mg/kg sodium pentobarbital i.p.) and hearts removed and perfused in Langendorff mode as described in detail previously (Du Toit et al., 2005; Du Toit et al., 2008; Maarman et al., 2012). Hearts were excised and transferred to $4^{\circ} \mathrm{C}$ perfusion fluid, the aorta was cannulated and coronary vessels perfused with modified Krebs- Henseleit buffer containing (in mM): $118 \mathrm{NaCl}, 25 \mathrm{NaHCO}_{3}, 4.7 \mathrm{KCl}, 1.75 \mathrm{CaCl}_{2}, 1.2 \mathrm{MgSO}_{4}, 11 \mathrm{D}$-glucose, and 0.5 EDTA at a pressure of $100 \mathrm{~cm} \mathrm{H}_{2} \mathrm{O}$. Perfusion fluid was saturated with $95 \% \mathrm{O}_{2}-5 \%$ $\mathrm{CO}_{2}$ at $37^{\circ} \mathrm{C}$ giving a $\mathrm{pH}$ of 7.4. A fluid-filled polyvinyl chloride balloon was inserted into the left ventricle and connected to a P23XL pressure transducer (Viggo-Spectramed, Oxnard, CA) for measurement of ventricular pressure. Balloon volume was adjusted to achieve an end-diastolic pressure of 4-6 mmHg. Functional data were recorded at $1 \mathrm{KHz}$ on a 4-channel MacLab system (ADInstruments, Castle Hill, Australia) connected to an Apple iMac computer. Peak systolic, diastolic and developed pressures, heart rate, and rates of contraction or relaxation over time $(\mathrm{dP} / \mathrm{d} t)$ were documented. Coronary flow was monitored via volumetric analysis of coronary effluent. 


\section{ACCEPTED MANUSCRIPT}

After balloon placement, hearts were immersed in a water-jacketed chamber maintained at

$37^{\circ} \mathrm{C}$. Perfusion fluid temperature was monitored using a thermistor probe (Model 52II,

Fluke Corporation, Everett, Western Australia) in the coronary sinus. Hearts were excluded

from study after a 15-min stabilization period if they failed to meet any of the following functional criteria: $i$ ) coronary flow $>20 \mathrm{ml} / \mathrm{min}, i i$ ) unstable (fluctuating) contractile function, iii) left ventricular systolic pressure $<90 \mathrm{mmHg}$, or $i v$ ) significant cardiac arrhythmias.

After an initial 15 min normoxic stabilization period, hearts were paced at 300 beats $/ \mathrm{min}$ (Grass S9 stimulator, Quincy, MA), normalizing rate to allow comparison of rate-dependent measures of contractile function (systolic and developed ventricular pressures) and inotropic state $(\mathrm{dP} / \mathrm{d} t)$. Baseline measures were made after 10 and $20 \mathrm{~min}$. The LAD was occluded for $40 \mathrm{~min}$ to induce regional ischaemia followed by $60 \mathrm{~min}$ of reperfusion achieved by ligature release. At the end of reperfusion the ligature was retied, the hearts stained with Evan's Blue dye and frozen overnight. Hearts were then sectioned and stained with TTC (Clark et al., 2011), to delineate viable and necrotic myocardium. Tissue areas (viable tissue, tissue at risk and necrotic tissue) were quantified by volumetric planimetry using a flat-bed scanner for image capture and computer software for image analysis (UTHSCSA Image Tool, V3). Infarct size is expressed as \% of area at risk (AAR).

\subsection{Blood biochemical analyses}

Animals set aside for blood biochemical analyses and myocardial tissue collection were fasted for $6 \mathrm{~h}$ before anaesthesia, blood collection and heart excision. Epididymal, peritoneal and retro-peritoneal fat was removed and weighed.

For serum analysis, blood samples were placed in serum separation tubes (BD Vacutainer 


\section{ACCEPTED MANUSCRIPT}

tubes), centrifuged and serum stored at $-80{ }^{\circ} \mathrm{C}$ for later analysis. Blood triglycerides, high density lipoprotein (HDL), cholesterol and glucose levels were determined in fresh wholeblood using a Blood-Lipid and Glucose Analyser (L.D.X. Cholestech Analyser, Alere ${ }^{\mathrm{TM}}$, Australia).

Levels of insulin (ALPCO Immunoassays ${ }^{\mathrm{TM}}$, Salem) and TBARS (R\&D systems, Minneapolis, MN, USA.) were determined in 96-well enzyme-linked immunosorbant assay's (ELISAs) according to manufacturer instructions.

Coronary effluent LDH activity was determined spectrophotometrically, as described previously (Peart and Headrick, 2003). To assess insulin resistance in all animals the homeostasis model assessment (HOMA) index was measured. Fasting blood glucose and

insulin levels were used to determine the HOMA index using the standard formula: [fasting insulin $(\mu \mathrm{IU} / \mathrm{ml}) \times$ fasting glucose $(\mathrm{mmol} / \mathrm{l})] / 22.5$.

\subsection{Myocardial enzyme activity assays}

Glutathione peroxidase (GPx) activity was measured spectrophotometrically using a method described by Flohe and Gunzler (1984) and adapted to work in a 96-well microplate. Thioredoxin reductase (TrxR) activity was quantified using a Thioredoxin Reductase Colorimetric Assay Kit (Cayman Chemicals, Ann Arbor, Michigan, USA).

\subsection{Western immunoblot analyses}

2.6.1. Tissue extraction. Hearts were sectioned and homogenised in a glass dounce with 1.0 $\mathrm{ml}$ of ice-cold isolation buffer containing protease and phosphatase inhibitors (70 $\mathrm{mM}$ sucrose, $190 \mathrm{mM}$ mannitol, $20 \mathrm{mM}$ HEPES and $0.2 \mathrm{mM}$ EDTA, $1 \mathrm{mM}$ PMSF, $10 \mu \mathrm{M}$ 


\section{ACCEPTED MANUSCRIPT}

leupeptin, $3 \mathrm{mM}$ benzamidine, $5 \mu \mathrm{M}$ pepstatin $\mathrm{A}, 1 \mathrm{mM} \mathrm{NaO}$ ). Whole homogenate samples were removed and stored in lysis buffer for later analysis. Tissue homogenates underwent centrifugation at $600 \mathrm{~g}(\mathrm{rcf})$ for $10 \mathrm{~min}$ at $4{ }^{\circ} \mathrm{C}$. The supernatant was removed and the nuclear pellet washed in isolation buffer containing protease and phosphatase inhibitors and spun at $600 \mathrm{~g}$ for $10 \mathrm{~min}$ before being re-suspended in lysis buffer and stored. The supernatant containing mitochondria, cytosol and plasma membrane was centrifuged at 10,000g for 30 min. The mitochondria enriched pellet was washed in isolation buffer at $600 \mathrm{~g}$ for $10 \mathrm{~min}$ and re-suspended in lysis buffer, with this and the non-mitochondrial fraction stored at $-80^{\circ} \mathrm{C}$ until analysis.

Protein concentrations were determined using a BCA assay in a 96-well microplate (Pierce BCA protein assay kit), with absorbance measured at $540 \mathrm{~nm}$ (Tecan infinite M200 Pro, Mannedorf, Switzerland). Aliquots of $20 \mu \mathrm{g}$ protein were prepared with appropriate volumes of Kinexus buffer and protease inhibitors (20 mM Mops, 2 mM EGTA; 5 mM EDTA; 30 $\mathrm{mM}$ sodium fluoride; $40 \mathrm{mM} \beta$-glycerophosphate; $20 \mathrm{mM}$ sodium tetrapyrophosphate) and stored at $-80^{\circ} \mathrm{C}$ until analysis.

\subsubsection{Electrophoresis: Myocardial or cell fractions containing equal quantities of protein} were loaded onto hand-cast $10 \%$ acrylamide gels and separated at $150 \mathrm{~V}$ for $80 \mathrm{~min}$. Transfer of proteins was achieved using a polyvinylidene difluoride fluorescent (PVDF) membrane at a $350 \mathrm{~mA}$ current for $\sim 2 \mathrm{~h}$, and blocked with Odyssey fish serum for a further $2 \mathrm{~h}$ at room temperature. Transferred proteins were incubated with primary antibody (dilution 1:7501:1000) for $15-18 \mathrm{~h}$ at $4^{\circ} \mathrm{C}$ with gentle rocking. The PVDF membrane was washed in TBS for $5 \mathrm{~min}$ and again in TBST ( 4 cycles of $5 \mathrm{~min}$ ) before incubation with secondary antibody at room temperature in the dark. Membranes were subsequently visualised on a Licor Odyssey 


\section{ACCEPTED MANUSCRIPT}

Infrared Imaging System (Millennium Science, Mulgrave, Australia) with protein densitometry normalised to an internal standard and loading control.

Primary antibodies that were used included: Mfn-1, Mfn-2, OPA-1, DRP-1 and Bax (Abcam, Cambridge, MA), and Bcl-2 and total and cleaved caspase-3 (Cell Signalling Technology Inc., Danvers, MA, USA).

\subsection{Statistical analyses}

Unless otherwise stated, all results are expressed as means \pm S.E.M. Differences between two or more groups were tested via 1- or 2-way ANOVA, with a Newman-Keuls post-hoc test applied when significant effects were detected. Significant differences were accepted for $\mathrm{P}<0.05$.

\section{Results}

\subsection{Effects of diet and pravastatin on body weight, body composition and cardiometabolic} risk factors

The HCFD significantly increased both body mass $(655 \pm 12 \mathrm{~g}$ for $\mathrm{C}$ vs. $736 \pm 15 \mathrm{~g}$ for HCFD, $\mathrm{P}<0.001)$ and fat mass $(153 \pm 21 \mathrm{~g}$ for $\mathrm{C}$ vs. $310 \pm 10 \mathrm{~g}$ for $\mathrm{HCFD}, \mathrm{P}<0.0001)$, with prava preventing the body mass change in HCFD animals (Table 1 and Fig. 1). The HCFD increased serum triglycerides and HOMA-IR (Table 2 and Fig. 2), and prava treatment prevented these increases. Blood glucose levels were unchanged and similar in all 4 groups. Plasma TBARS, reflecting systemic lipid peroxidation, were unaltered by the HCFD, and selectively increased by prava treatment in HCFD animals (Fig. 3). 


\section{ACCEPTED MANUSCRIPT}

3.2. Effects of diet and pravastatin on myocardial function and reperfusion $L D H$ release and infarct size

Neither diet nor pravastatin treatment influenced myocardial basal or post-ischaemic mechanical function. Post-ischaemic myocardial LDH release was similar for all groups (data not presented), however infarct size was increased in HCFD animals. Despite improving myocardial cardiometabolic risk factors (triglyceride levels and HOMA-IR) in HCFD animals, prava had no effects on myocardial infarction: infarct size was similar in the prava treated control and HCFD fed animals (Fig. 4).

\subsection{Effects of diet and pravastatin on myocardial GPX and TrxR activities}

The HCFD had no effect on myocardial glutathione peroxidase activity but decreased thioredoxin reductase activity compared to the control diet fed animals (Fig. 5A and 5B). Prava reduced cardiac glutathione peroxidase activity in HCFD animals (Fig. 5A) but had no effect on thioredoxin reductase activity.

\subsection{Effects of diet and pravastatin on myocardial expression of proteins regulating mitochondrial fission/fusion and apoptosis}

The HCFD decreased mitochondrial MFN-1 and increased mitochondrial DRP-1 expression without effecting MFN-2, OPA-1 or cytosolic DRP-1 levels (Fig. 6A-E). Prava decreased mitochondrial MFN-1 expression in control diet animals without modifying MFN-2 or OPA1 (Fig. 6A, Fig. 6B and Fig. 6C). However, prava was without effect on these proteins in HCFD rats. Mitochondrial DRP-1 expression was insensitive to prava in control animals while levels in HCFD fed rats were reduced by treatment (Fig. 6D). Prava had no effect on cytosolic DRP-1 expression in either the control or HCFD fed animals (Fig. 6E). Overall, the 


\section{ACCEPTED MANUSCRIPT}

HCFD promotes pro-fusion changes (decreased ratio of MFN1:DRP1) (Fig. 6F) that are countered by prava treatment.

In terms of apoptotic proteins, while there was a tendency to increased mitochondrial Bax, the HCFD had no significant effects on cardiac Bax, Bcl2, the Bax:Bcl2 ratio or caspase-3 levels (Fig. 7A-E). Nonetheless, prava treatment significantly decreased mitochondrial Bax expression in HCFD animals (Fig. 7A), and cytosolic Bax (Fig. 7B) and caspase-3 levels (Fig. 7E) in both control and HCFD animals. Prava treatment had no significant effect on cleaved caspase-3 expression in either control or HCFD animals (Fig. 7F). The mitochondrial Bax:Bcl-2 ratio was unaltered by diet or prava (Fig. 7D). Thus, HCFD does not appear to induce pro-apoptotic protein changes, while prava generally reduces pro-apoptotic proteins in hearts from both lean and obese groups.

\section{Discussion}

In this study we demonstrate that a HCFD increases body weight, serum triglycerides and insulin-resistance, and worsens myocardial infarct tolerance without influencing baseline cardiac function. This effect is associated with reduced myocardial TrxR (not GPX) activity, and reduced mitochondrial MFN-1 vs. increased DRP-1 expression, without consistent changes in apoptosis proteins. While prava treatment prevented key risk factor changes (increased weight, adiposity, triglycerides, HOMA-IR) in HCFD animals, the drug had no effect on myocardial infarct size. This may reflect complex pleiotropic effects of prava on anti-oxidant, mitochondrial fusion:fusion and apoptosis proteins: prava decreased GPX activity in HCFD hearts, reduced mitochondrial MFN1 levels in control but not HCFD hearts while selectively countering the HCFD-dependent increase in mitochondrial DRP-1, and 


\section{ACCEPTED MANUSCRIPT}

reduced cytosolic Bax and caspase-3 levels in both groups while reducing mitochondrial Bax specifically in HCFD hearts.

\subsection{Effects of the HCFD and pravastatin on morphometric and cardiometabolic risk factors}

\subsubsection{Body weight and body composition: Effects of a HCFD on body weight and}

composition in rodents are well characterized (Arkari et al., 2008; Wensley et al, 2013; Salie et al., 2014), confirmed here with significantly increased body and body fat mass. The increased body weight was primarily due to increased fat mass, with DXA scans revealing significantly increased fat mass and marginally decreased lean mass in HCFD animals. Effects of statins on body weight remain controversial, with studies reporting either increased (Kang et al, 2009), unaltered (Yamada et al., 2017; Sun et al., 2017) or decreased (Araki et al., 2008; Fraulob et al., 2012; Zhang et al., 2017; Cui et al., 2017) weight with statin therapy. Here prava treatment did attenuate the HCFD-induced increase in body weight. This corroborates observations of Dalaklioglu and co-workers (2013) who documented slight body weight reduction with prava treatment in rats. To our knowledge no other animal studies have reported on the body weight effects of chronic prava treatment. While physical activity was not measured, changes are unlikely to contribute to (indeed may act to counter) this weight loss effect given evdence of statin-dependent reductions in physcial activity and exercise capacity in both humans and rodents (Meador and Huey, 2010; Bouitbir et al., 2011; Lee et al., 2014).

\subsubsection{Blood lipids and insulin sensitivity: Dietary obesity was accompanied by anticipated} increases in circulating triglycerides and HOMA-IR values. These data corroborate our previous findings (Du, Toit et al 2008; Wensley et al 2013) and those of others (Araki et al., 2008; Lalli et al., 2008). Pravastatin treatment decreased triglyceride levels in HCFD obese but not control lean rats. This triglyceride lowering effect is consistent with reported efficacy 


\section{ACCEPTED MANUSCRIPT}

of prava in decreasing triglycerides in obese (Araki et al., 2008) and hypercholesterolaemic mice (Lorza-Gil et al., 2016), and in clinical trials in dyslipidaemic patients (Barakat et al., 2013 Schweitzer et al 2002; Baker et al., 2010).

Dyslipidaemia is implicated in the aetiology of insulin-resistance and diabetes (Eckel, et al., 2010 Yoon et al., 2016, Chrysant, 2017). Management is thus predicted to improve insulin sensitivity and prevent or delay onset of frank diabetes. Paradoxically, emerging evidence suggests lipid lowering statins may actually exacerbate insulin-resistance and accelerate onset of diabetes (Preiss et al. 2012; Muscogiuri et al., 2014; Bellia et al., 2012; Sato et al., 2012). Nonetheless, data regarding effects of statins on insulin sensitivity are controversial. One study found that while atorvastatin increased HOMA-IR and fasting insulin in rats, pravastatin had no effect on these parameters (Beltowski et al., 2011). Two other animal studies demonstrated that lovastatin improved insulin sensitivity in high-fat fed rats (Lalli et al., 2008) and rosuvastatin had similar effects in high-fat fed mice (Fraulob et al., 2012).

Several clinical trials have shown prava can improve lipid profiles and insulin sensitivity. Pravastatin improved lipid profiles and insulin sensitivity in dyslipidaemic, insulin insensitive patients (Sugiyama et al., 2007; Koh et al., 2013) while pravastatin/valsartan combination therapy had additive effects and improved these parameters above values observed with monotherapy (Koh et al., 2013).

\subsection{Effects of the HCFD and pravastatin on myocardial infarct size}

Ourselves (Du Toit et al., 2008; Wensley et al., 2013, Donner et al., 2016) and others (Huisamen et al., 2011) present evidence that diet-induced obesity with insulin-resistance decreases myocardial tolerance to ischaemia. This is confirmed here, with infarct size increased in obese, insulin-resistant rats when compared with control littermates (Fig. 4). Chronic prava treatment, however, had no effect on infarct size in lean or obese HCFD 


\section{ACCEPTED MANUSCRIPT}

animals, despite other benefits. This agrees with an early study of the effects of chronic statin therapy on post ischaemic functional outcomes in pigs, which found no benefit with 3 weeks of pre-ischaemic treatment with either simvastatin, atorvastatin or pravastatin (Rendig et al., 2003). In contrast, several studies exploring the effects of acute or short-term (minutes to days) statin treatment support reductions in myocardial I/R injury. A 3 day atorvastatin treatment regime or bolus injection 15 min before ischaemia reportedly decreases myocardial infarct size in rats (Ye et al., 2006; Ye et al 2008), and simvastatin administered 20 min prior to ischaemia decreases infarct size in rabbits (Bao et al., 2009) and mice (Andres et al., 2014). The acuteness of benefit in these studies further highlights the pleiotropic basis of cardiac protection. Data from clinical studies are less consistent, with a study by Post et al. (2012) suggesting that 1 week of atorvastatin treatment prior to percutaneous coronary intervention had no impact on infarct size, while another study reported decreased troponin I levels in unstable angina patients receiving long-term high-dose statin therapy (Gordin et al., 2012). Chronic statin therapy is associated with a reduction in major adverse cardiac events in myocardial infarct patients (Piao et al., 2017), consistent with its risk reduction effects, however treatment also improved post-infarct mechanical function, suggesting potentially direct myocardial effects (Auscher et al., 2017).

\subsection{Effects of the HCFD and pravastatin on anti-oxidant enzyme activities}

The effects of obesity on anti-oxidant enzyme activity are well characterized (Utus and Picklo, 2011; Panday et al., 2015). Here we found there was a marginal decline in myocardial GPX activity and significant decrease in thioredoxin reductase activity in HCFD fed animals. A reduction in thioredoxin reductase activity has been recently reported in HCFD fed rats (Shrivastava et al., 2013). However, effects of statins on oxidative stress and anti-oxidant enzyme activity are more controversial. Here, prava decreased myocardial GPX activity in HCFD animals, consistent with reduced serum GPX activity in coronary artery 


\section{ACCEPTED MANUSCRIPT}

disease patients treated with statins (Palazhy et al. 2015). However, an earlier study found no effect of prava on plasma GPX activity in hypercholesterolaemic patients (Chen et al., 1997). These observations are challenged by a study showing that rosuvastatin increases GPX activity in obese rats fed a high fat diet (Ansari et al., 2012).

The reduction in GPX activity in the HCHF+Prava animals here was also accompanied by an increase in serum TBARS. Since TBARS are a measure of free radical induced lipid peroxidation there appears a clear link between reduced anti-oxidant enzyme activity and increased lipid peroxidation in obese prava treated animals. Increased oxidative stress, in turn, is a well established driver of apoptosis (Abdel-Hamidand Firgany, 2015; Manickam et al., 2017). In the current study this reduction in GPX activity in the HCHF+Prava group may contribute to increased apoptosis.

\subsection{Effects of the HCFD and pravastatin on mitochondrial fission/fusion and apoptosis proteins}

4.4.1. Effects of the HCFD: Shifts in autophagy and apoptosis on transition from obesity to the metabolic syndrome have been characterised (Li et al., 2012), whereas effects of dietary obesity on mitochondrial fission and fusion are less well researched. We demonstrate that a HCFD that induces significant obesity and insulin-resistance decreases pro-fusion MFN-1 and increases pro-fission DRP-1 in cardiac mitochondria without modifying MFN-2 or OPA1 levels. These differential changes in mitochondrial DRP-1 vs. MFN1 are predicted to favour fission, in turn promoting post-ischaemic cell death (Calo et al., 2013). This effect is thought to involve shifts in Bcl2 proteins (Aouacheria et al., 2017), and the HCFD did increase mitochondrial Bax levels, although Bcl-2, the Bax:Bcl-2 ratio and cytosolic levels of total and cleaved caspase-3 were unchanged. These observations contrast reports of increased 


\section{ACCEPTED MANUSCRIPT}

apoptosis and pro-apoptotic proteins in porcine (Li et al., 2012) and rodent (Ballal et al., 2010) models of obesity and metabolic syndrome.

The effects of HCFD and obesity on mitochondrial dynamics and the proteins regulating this process are controversial. Decreased mitochondrial levels of pro-fusion MFN-1 and increased levels of pro-fission DRP-1 in HCFD hearts here are consistent with the findings of Jheng and co-workers who report palmitate-induced increases in DRP-1 expression, mitochondrial fragmentation and insulin-resistance in $\mathrm{C} 2 \mathrm{Cl} 2$ muscle cells (Jheng et al., 2012), together with increased skeletal muscle DRP-1 and fission-dependent insulin-resistance in $o b / o b$ mice (Jheng et al., 2012). Other work shows that in utero and post-weaning exposure of rats to an obesogenic HCFD reduces Mfn1/2 and OPA-1 mRNA levels in muscle and liver (Borengasser et al., 2014), and that repression of Mfn-2 promotes mitochondrial fragmentation and inhibits glucose oxidation and respiration in humans (Bach et al., 2003). Obesity has been shown to reduce Mfn-2 expression, potentially contributing to disrupted mitochondrial dynamics (Bach et al., 2003).

4.4.2. Effects of Pravastatin: The effects of statins on myocyte structure and function are not well defined, though a range of pleiotropic cardiovascular actions have been revealed in recent years (Oesterle et al., 2017). Here prava improved body weight, circulating lipids and insulin sensitivity without influencing myocardial infarct size or LDH release. This may reflect complex pleiotropic effects of the drug in myocardium. Pravastatin decreased mitochondrial MFN1 in control but not HCFD hearts, while decreasing DRP-1 expression in HCFD but not control hearts without modifying MFN2 or OPA-1 expression (ie. decreased MFN1:DRP-1 ratio in control diet $v s$. increased ratio in HCFD hearts). Chronic repression of DRP-1 expression may promotes fission and mitophagy, promoting mitochondrial depletion and cardiomyopathy (Song et al., 2015). In contrast, acute repression of DRP-1 during an I/R event may be protective (Jin et al., 2018). While cardiac function was unaltered after 8 week 


\section{ACCEPTED MANUSCRIPT}

prava treatment, we cannot exclude the possibility that prava promoted fission and mitophagy in our study. The absence of an improvement in infarct size with prava, despite repression of DRP-1 expression, suggest that chronic prava (with potential mitochondrial depletion) may counter possible cardioprotective effects of DRP-1 repression during I/R.

Changes in apoptotic proteins were similarly complex: prava selectively decreased mitochondrial levels of pro-apoptotic Bax and anti-apoptotic Bcl2 in HCFD but not control hearts, and repressed cytosolic levels of Bax and total (but not cleaved) caspase- 3 in both groups. These changes in pro- and anti-apoptotic proteins are difficult to interpret in terms of predicting effects on cell death, with little evidence of an overt pro- or anti-apoptotic effect of prava at the regulatory protein level. Shifts in Bax and Bcl2 are balanced such that the Bax:Bcl2 ratio is unaltered, and reduced total caspase 3 without a change in cleaved caspase3 levels suggests prava may decrease apoptotic 'potential' (ie. the caspase-3 pool available for cleavage) without directly influencing execution of caspase-3 dependent apoptosis. Potential effects on cell death are additionally complicated by reduced GPX expression with prava in HCFD hearts, and differential changes in fusion:fission proteins, which may influence the balance of cell survival vs. death. Interestingly, early studies of the cardioprotective effects of statins suggest that acute simvastatin may limit I/R injury via upregulating mitophagy (Andres et al., 2014). Other work suggests that DRP-1 mediates protective mitophagy during metabolic insult such as I/R (Ikeda et al., 2015). Nonetheless, considerable attention has focused on DRP-1 inhibition in cardioprotection (Mukherjee et al., 2015), despite important questions and potential limitations regarding such a strategy (Dong et al., 2016; Rosdah et al., 2016). 


\section{ACCEPTED MANUSCRIPT}

\section{Conclusions}

The current study indicates that despite improvements in key systemic risk factors (including body weight, insulin-resistance and triglyceride levels), prava treatment failed to limit the exaggeration of myocardial infarction observed in dietary obesity with insulin-resistance. This increase in infarction in HCFD is consistent with impaired anti-oxidant activity, increased mitochondrial Bax, and increased fission (DRP-1) vs. fusion (MFN1) protein expression. The lack of a cardioprotective effect of prava may reflect diverse pleiotropic effects of the statin, which induced opposing changes in proteins governing apoptosis, fusion and fission, while suppressing cardiac GPX activity. The basis and impacts of these distinct molecular changes, which highlight the complexities of statin effects in healthy and diseased hearts, warrant further study. 


\section{ACCEPTED MANUSCRIPT}

\section{Acknowledgements and disclosures}

This study was supported by funds from the Griffith University Research Grant scheme and the Griffith Health Institute. We wish to thank Owain Evans for his technical assistance with the TrxR and GPX activity assays.

No conflicts of interest, financial or otherwise, are declared by the authors.

\section{Author contributions}

Conceived and designed experiments: EFDT, DD.

Performed the experiments: EFDT, DD, LW, BB, MO.

Analysed the data: EFDT, MO, LW, BB, JP.

Interpreted data: EFDT, JH, MO JP

Prepared the figures and manuscript: EFDT, JH, MO, LW. 


\section{References.}

Abdel-Hamid AA1, Firgany Ael-D Atorvastatin alleviates experimental diabetic cardiomyopathy by suppressing apoptosis and oxidative stress. J Mol Histol. 2015 Oct;46(45):337-45.

Andres AM, Hernandez G, Lee P, Huang C, Ratliff EP, Sin J, Thornton CA, Damasco MV, Gottlieb RA. Mitophagy is required for acute cardioprotection by simvastatin. Antioxid Redox Signal. 2014 Nov 10;21(14):1960-73.

Ansari JA, Bhandari U, Haque SE, Pillai KK. Enhancement of antioxidant defense mechanism by pitavastatin and rosuvastatin on obesity-induced oxidative stress in Wistar rats. Toxicol Mech Methods. 2012 Jan;22(1):67-73.

Allen SC and Mamotte CDS. Pleiotropic effects of statins - Do epigenetics play a role? JPET 2017 August;362:319-326.

Aouacheria A, Baghdiguian S, Lamb HM, Huska JD, Pineda FJ, Hardwick JM. Connecting mitochondrial dynamics and life-or-death events via Bcl-2 family proteins. Neurochem Int. 2017 Apr 28. pii: S0197-0186(17)30186-9.

Araki H, Nishihara T, Matsuda M, Fukuhara A, Kihara S, Funahashi T, Kataoka TR, Kamada Y, Kiyohara T, Tamura S, Hayashi N, Shimomura I. Adiponectin plays a protective role in caerulein-induced acute pancreatitis in mice fed a high-fat diet. Gut. 2008 Oct;57(10):143140.

Auscher S, Løgstrup BB, Møller JE, Vinther KH, Lambrechtsen J, Egstrup K. Effects of Intensive Statin Therapy on Left Ventricular Function in Patients with Myocardial Infarction and Abnormal Glucose Tolerance. Cardiology. 2017 May 18;138(1):16-25.

Bao N, Ushikoshi H, Kobayashi H, Yasuda S, Kawamura I, Iwasa M, Yamaki T, Sumi S, Nagashima K, Aoyama T, Kawasaki M, Nishigaki K, Takemura G, Minatoguchi S. 


\section{ACCEPTED MANUSCRIPT}

Simvastatin reduces myocardial infarct size via increased nitric oxide production in normocholesterolemic rabbits. J Cardiol. 2009 Feb;53(1):102-7

Bach D, Pich S, Soriano FX, Vega N, Baumgartner B, Oriola J, Daugaard JR, Lloberas J, Camps M, Zierath JR, Rabasa-Lhoret R, Wallberg-Henriksson H, Laville M, Palacín M, Vidal H, Rivera F, Brand M, Zorzano A. Mitofusin-2 determines mitochondrial network architecture and mitochondrial metabolism. A novel regulatory mechanism altered in obesity. J Biol Chem. 2003 May 9;278(19):17190-7.

Baker WL, Talati R, White CM, Coleman CI. Differing effect of statins on insulin sensitivity in non-diabetics: a systematic review and meta-analysis. Diabetes Res Clin Pract. 2010 Jan;87(1):98-107.

Ballal K, Wilson CR, Harmancey R, Taegtmeyer H. Obesogenic high fat western diet induces oxidative stress and apoptosis in rat heart. Mol Cell Biochem. 2010 Nov;344(1-2):221-30. Barakat L1, Jayyousi A, Bener A, Zuby B, Zirie M. Comparison of Efficacy and Safety of Rosuvastatin, Atorvastatin and Pravastatin among Dyslipidemic Diabetic Patients. ISRN Pharmacol. 2013;2013:146579.

Bellia A, Rizza S, Lombardo MF, Donadel G, Fabiano R, Andreadi K, Quon MJ, Sbraccia P, Federici M, Tesauro M, Cardillo C, Lauro D. Deterioration of glucose homeostasis in type 2 diabetic patients one year after beginning on statins therapy. Atherosclerosis. 2012 223:197203, 2012.

Bełtowski J, Atanassova P, Chaldakov GN, Jamroz-Wiśniewska A, Kula W, Rusek M. Opposite effects of pravastatin and atorvastatin on insulin sensitivity in the rat: role of vitamin D metabolites. Atherosclerosis. 2011 Dec;219(2):526-31.

Borengasser SJ, Faske J, Kang P, Blackburn ML, Badger TM, Shankar K. In utero exposure to prepregnancy maternal obesity and postweaning high-fat diet impair regulators of mitochondrial dynamics in rat placenta and offspring. Physiol Genomics. 2014 Dec 


\section{ACCEPTED MANUSCRIPT}

$1 ; 46(23): 841-50$.

Bouhidel O, Pons S, Souktani R, Zini R, Berdeaux A, Ghaleh B. Myocardial ischemic postconditioning against ischemia-reperfusion is impaired in ob/ob mice. American journal of physiology. Heart and Circulatory Physiology. 2008 295(4):H1580-1586.

Bouitbir J, Charles AL, Rasseneur L, Dufour S, Piquard F, Geny B, Zoll J. Atorvastatin treatment reduces exercise capacities in rats: involvement of mitochondrial impairments and oxidative stress. J Appl Physiol (1985). 2011 Nov;111(5):1477-83.

Butterick TA, Hocum Stone L, Duffy C, Holley C, Cabrera JA, Crampton M, Ward HB, Kelly RF, McFalls E. Pioglitazone increases PGC1- $\alpha$ signaling within chronically ischemic myocardium. Basic Res Cardiol. 2016 May;111(3):37.

Calo L, Dong Y, Kumar R, Przyklenk K, Sanderson TH. Mitochondrial dynamics: an emerging paradigm in ischemia-reperfusion injury. Curr Pharm Des. 2013;19(39):6848-57.

Chen MF1, Hsu HC, Lee YT. Short-term treatment with low-dose pravastatin attenuates oxidative susceptibility of low-density lipoprotein in hypercholesterolemic patients.

Cardiovasc Drugs Ther. 1997 Dec;11(6):787-93.

Chess DJ and Stanley WC. Role of diet and fuel overabundance in the development and progression of heart failure. Cardiovascular Research 2008;79(2): 269-278.

Chrysant SG. New onset diabetes mellitus induced by statins: current evidence. Postgrad Med. 2017 May;129(4):430-435.

Clark C, Smith W, Lochner A, du Toit EF. The effects of gender and obesity on myocardial tolerance to ischemia. Physiological research/Academia Scientiarum Bohemoslovaca 2011;60(2): 291-301.

Cui X, Long C, Zhu J, Tian J. Protective Effects of Fluvastatin on Reproductive Function in Obese Male Rats Induced by High-Fat Diet through Enhanced Signaling of mTOR. Cell Physiol Biochem. 2017;41(2):598-608. 


\section{ACCEPTED MANUSCRIPT}

Dalaklioglu S, Sahin S, Tasatargil A, Celik-Ozenci C. Pravastatin Improves the Impaired

Nitric Oxide-Mediated Neurogenic and Endothelium-Dependent Relaxation of Corpus

Cavernosum in Aged Rats. Aging Male 2013;17 (4), 259-266.

Dong Y, Undyala VVR, Przyklenk K. Inhibition of mitochondrial fission as a molecular target for cardioprotection: critical importance of the timing of treatment. Basic Res Cardiol. 2016;111(5):59.

Donner D, Headrick JP, Peart JN, du Toit EF. Obesity improves myocardial ischaemic tolerance and RISK signalling in insulin-insensitive rats. Disease Models \& Mechanisms. 2013;6(2):457-66.

Donner DG, Elliott GE, Beck BR, Bulmer AC, Lam AK, Headrick JP, Du Toit EF.

Trenbolone Improves Cardiometabolic Risk Factors and Myocardial Tolerance to IschemiaReperfusion in Male Rats With Testosterone-Deficient Metabolic Syndrome. Endocrinology. $2016 ; 157(1): 368-81$.

Dumas JF, Simard G, Flamment M, Ducluzeau PH, Ritz P. Is skeletal muscle mitochondrial dysfunction a cause or an indirect consequence of insulin resistance in humans? Diabetes Metab. 2009;35:159-67.

Du Toit EF, Smith W, Muller C, Strijdom H, Stouthammer B, Woodiwiss AJ, et al. Myocardial susceptibility to ischemic-reperfusion injury in a prediabetic model of dietaryinduced obesity. American journal of physiology. Heart and circulatory physiology 2008;294(5): H2336-2343.

Eckel RH, Alberti KG, Grundy SM and Zimmet PZ. The metabolic syndrome. The Lancet 2010;375(9710): 181-183.

Flohé L and Günzler WA. Assays of glutathione peroxidase. Methods Enzymol. $1984 ; 105: 114-21$. 


\section{ACCEPTED MANUSCRIPT}

Fraulob J, Souza-Mello V, Aguila MB, Mandarim-de-Lacerda CA. Beneficial effects of rosuvastatin on insulin resistance, adiposity, inflammatory markers and non-alcoholic fatty liver disease in mice fed on a high-fat diet. Clinical Science 2012;123:259-270.

Gonzalez-Franquesa A and Patti M-E. Insulin Resistance and Mitochondrial Dysfunction. Santulli (ed.), Mitochondrial Dynamics in Cardiovascular Medicine, Advances in Experimental Medicine and Biology 982, 2015.

Gordin J, Haider A, Swaminathan RV, Kim LK, Minutello RM, Bergman G, Wong SC, Feldman DNImpact of long-term statin therapy on postprocedural myocardial infarction in patients undergoing nonemergency percutaneous coronary intervention. Am J Cardiol. 2012 Nov 15;110(10):1397-404.

Gu Q, Paulose-Ram R, Burt VL, Kit BK. Prescription cholesterol-lowering medication use in adults aged 40 and over: United States, 2003-2012. NCHS Data Brief. 2014 Dec;(177):1-8. Guo H, Lv H, Tang W, Chi J, Liu L, Xu F, Ji Z, Zhai X, Peng F. Rosuvastatin may modulate insulin signalling and inhibiot atherogenesis beyond its plasma cholesterol lowering effects in insulin resistant mice. Cardiovasc Drugs Ther 2012;26:375-382.

Huisamen B, Genis A, Marais E, Lochner A. Pre-treatment with a DPP-4 inhibitor is infarct sparing in hearts from obese, pre-diabetic rats. Cardiovasc Drugs Ther. 2011 Feb;25(1):1320.

Ikeda Y, Shirakabe A, Maejima Y, Zhai P, Sciarretta S, Toli J, Nomura M, Mihara K, Egashira K, Ohishi M, Abdellatif M, Sadoshima J. Endogenous Drp1 mediates mitochondrial autophagy and protects the heart against energy stress. Circ Res. 2015 Jan 16;116(2):264-78. Jheng HF, Tsai PJ, Guo SM, Kuo LH, Chang CS, Su IJ, Chang CR, Tsai YS. Mitochondrial fission contributes to mitochondrial dysfunction and insulin resistance in skeletal muscle. Mol Cell Biol. 2012 Jan;32(2):309-19. 


\section{ACCEPTED MANUSCRIPT}

Jin Q, Lia R, Hud N, Xin T, Zhu P, Hu S, Ma S, Zhu H, Ren J, Zhou H. DUSP1 alleviates cardiac ischemia/reperfusion injury by suppressing the Mff-required mitochondrial fission and Bnip3-related mitophagy via the JNK pathways. Redox Biology 14 (2018) 576-587. Kang CS, Chang NC, Chang ST, Lin CC, Lee TM. Effect of pravastatin on nephroprotection in deoxycorticosterone acetate-salt hypertensive rats. J Hypertens. 2009 Nov;27(11):2232-43. Kannel WB, Dawber TR, Kagan A, Revotskie N, Stokes J, 3rd. Factors of risk in the development of coronary heart disease--six year follow-up experience. The Framingham Study. Annals of internal medicine 1961;55: 33-50.

Koh KK, Lim S, Choi H, Lee Y, Han SH, Lee K, Oh PC, Sakuma I, Shin EK, Quon MJ. Combination pravastatin and valsartan treatment has additive beneficial effects to simultaneously improve both metabolic and cardiovascular phenotypes beyond that of monotherapy with either drug in patients with primary hypercholesterolemia. Diabetes. 2013 Oct;62(10):3547-52.

Koh KK, Quon MJ, Sakuma I, Han SH, Choi H, Lee K, Shin EK. Differential metabolic effects of rosuvastatin and pravastatin in hypercholesterolemic patients.Int J Cardiol. 2013 Jun 20;166(2):509-15.

Lakka HM, Laaksonen DE, Lakka TA, Niskanen LK, Kumpusalo E, Tuomilehto J, Salonen JT. The metabolic syndrome and total and cardiovascular disease mortality in middle-aged men. JAMA 2002;288(21):2709-16.

Lalli CA, Pauli JR, Prada PO, Cintra DE, Ropelle ER, Velloso LA, Saad MJA. Statin modulates insulin signaling and insulin resistance in liver and muscle of rats fed a high-fat diet. Metabolism. 2008 Jan;57(1):57-65

Lee DS, Markwardt S, Goeres L, Lee CG, Eckstrom E, Williams C, Fu R, Orwoll E, Cawthon PM, Stefanick ML, Mackey D, Bauer DC, Nielson CM. Statins and physical 


\section{ACCEPTED MANUSCRIPT}

activity in older men: the osteoporotic fractures in men study. JAMA Intern Med. 2014 Aug;174(8):1263-70

Li ZL, Woollard JR, Ebrahimi B, Crane JA, Jordan KL, Lerman A, Wang SM, Lerman LO. Transition from obesity to metabolic syndrome is associated with altered myocardial autophagy and apoptosis. Arterioscler Thromb Vasc Biol. 2012 May;32(5):1132-41.

Li S, Li H, Yang D, Yu X, Irwin DM, Niu G, Tan H. Excessive Autophagy Activation and Increased Apoptosis Are Associated with Palmitic Acid-Induced Cardiomyocyte Insulin Resistance.J Diabetes Res. 2017;2017:2376893.

Lorza-Gil E1, Salerno AG1, Wanschel AC1, Vettorazzi JF1, Ferreira MS2, Rentz T1, Catharino RR2, Oliveira HC. Chronic use of pravastatin reduces insulin exocytosis and increases $\beta$-cell death in hypercholesterolemic mice. Toxicology. 2016 Feb 17;344-346:4252.

Lopaschuk GD, Folmes CD, Stanley WC (2007). Cardiac energy metabolism in obesity. Circulation research 2007;101(4): 335-347.

Maarman G, Marais E, Lochner A, du Toit EF.Effect of chronic CPT-1 inhibition on myocardial ischemia-reperfusion injury (I/R) in a model of diet-induced obesity. Cardiovasc Drugs Ther. 2012 Jun;26(3):205-16

Manickam V, Periyasamy M, Dhakshinamoorthy V, Panneerselvam L, Perumal E. Recurrent exposure to ferric oxide nanoparticles alters myocardial oxidative stress, apoptosis and necrotic markers in male mice. Chemico-Biological Interactions. 2017;278:54-64.

Meador BM, Huey KA. Statin-associated myopathy and its exacerbation with exercise. Muscle Nerve. 2010;42(4):469-479.

Montgomery MK and Turner N. Mitochondrial dysfunction and insulin resistance: an update. Endocr Connect. 2015 Mar 1; 4(1): R1-R15. 


\section{ACCEPTED MANUSCRIPT}

Mukherjee UA, Ong SB, Ong SG, Hausenloy DJ. Parkinson's disease proteins: Novel mitochondrial targets for cardioprotection.Pharmacol Ther. 2015 Dec;156:34-43. Review. Muscogiuri G, Sarno G, Gastaldelli A, Savastano S, Ascione A, Colao A, Orio F. The good and bad effects of statins on insulin sensitivity and secretion. Endocr Res. 2014;39(4):137-43. Oesterle A, Laufs U, Liao JK. Pleiotropic Effects of Statins on the Cardiovascular System. Circ Res. 2017; 120: 229-243.

O'Keeffe A, Nazareth I and Petersen I. Time trends in the prescription of statins for the primary prevention of cardiovascular disease in the United Kingdom: a cohort study using The Health Improvement Network primary care data. Clin Epidemiol. 2016; 8: 123-132. Palazhy S, Kamath P, Vasudevan DM. Elevated oxidative stress among coronary artery disease patients on statin therapy: A cross sectional study. Indian Heart J. 2015 MayJun;67(3):227-32.

Panz V, Immelman A, Paiker J, Pilcher G, Raal F. High dose statin therapy does not induce inculin resistance in patients with familial hypercholesterolaemia. Metab Syndr Relat Disord. 2012;10(5):351-357.

Pandey G, Shihabudeen MS, David HP, Thirumurugan E, Thirumurugan K. Association between hyperleptinemia and oxidative stress in obese diabetic subjects. J Diabetes Metab Disord. 2015 Apr 14;14:24.

Peart J, Headrick JP. Adenosine-mediated early preconditioning in mouse: protective signaling and concentration dependent effects. Cardiovasc Res. 2003 Jun 1;58(3):589-601. Piao ZH, Jin L, Kim JH, Ahn Y, Kim YJ, Cho MC, Kim CJ, Kim HS, Liu B, Jeong MH; Other Korea Acute Myocardial Infarction Registry (KAMIR) Investigators.Benefits of Statin Therapy in Patients With Acute Myocardial Infarction With Serum Low-Density Lipoprotein Cholesterol $\leq 50$ mg/dl. Am J Cardiol. 2017 Apr 27. pii: S0002-9149(17)30691-4 


\section{ACCEPTED MANUSCRIPT}

Post S, Post MC, van den Branden BJ, Eefting FD, Goumans MJ, Stella PR, van Es HW, Wildbergh TX, Rensing BJ, Doevendans PA. Early statin treatment prior to primary PCI for acute myocardial infarction: REPERATOR, a randomized placebo-controlled pilot trial. Catheter Cardiovasc Interv. 2012 Nov 1;80(5):756-65.

Preiss D, Sattar N. Pharmacotherapy: statins and new-onset diabetes-the important questions. Nat Rev Cardiol. 2012;9:190-192.

Rendig SV1, Symons JD, Amsterdam EA. Effects of statins on myocardial and coronary artery response to ischemia-reperfusion. Can J Physiol Pharmacol. 2003 Nov;81(11):1064-71. Rosdah AA, K Holien J, Delbridge LM, Dusting GJ, Lim SY. Mitochondrial fission - a drug target for cytoprotection or cytodestruction? Pharmacol Res Perspect. 2016 Apr 21;4(3):e00235.

Salie R, Huisamen B, Lochner A. High carbohydrate and high fat diets protect the heart against ischaemia/reperfusion injury. Cardiovasc Diabetol. 2014 Jul 18;13:109.

Sato $\mathrm{H}$ et al. Statin intake is associated with decreased insulin sensitivity during cardiac surgery. Diabetes Care 2012;35;10:2095-2099.

Schweitzer M, Tessier D, Vlahos WD, Leiter L, Collet JP, McQueen MJ, Harvey L, Alaupovic P. A comparison of pravastatin and gemfibrozil in the treatment of dyslipoproteinemia in patients with non-insulin-dependent diabetes mellitus. Atherosclerosis. 2002 May;162(1):201-10.

Shrivastava A, Chaturvedi U, Singh SV, Saxena JK, Bhatia G. Lipid lowering and antioxidant effect of miglitol in triton treated hyperlipidemic and high fat diet induced obese rats. Lipids. 2013 Jun;48(6):597-607.

Song M, Gong G, Burelle Y, Gustafsson ÅB, Kitsis RN, Matkovich SJ, Dorn GW. Interdependence of Parkin-Mediated Mitophagy and Mitochondrial Fission in Adult Mouse Hearts. Circ Res. 2015 Jul 31;117(4):346-51. 


\section{ACCEPTED MANUSCRIPT}

Stewart J. Primary prevention of cardiovascular disease: A review of contemporary guidance and literature. RSM Cardiovasc Dis. 2017 Jan-Dec; 6: 2048004016687211.

Sugiyama S, Fukushima H, Kugiyama K, Maruyoshi H, Kojima S, Funahashi T, Sakamoto T, Horibata Y, Watanabe K, Koga H, Sugamura K, Otsuka F, Shimomura I, Ogawa

H.Pravastatin improved glucose metabolism associated with increasing plasma adiponectin in patients with impaired glucose tolerance and coronary artery disease. Atherosclerosis. 2007 Oct;194(2):e43-51.

Sun J, Bao J, Shi Y, Zhang B, Yuan L, Li J, Zhang L, Sun M, Zhang L, Sun W. Effect of simvastatin on MMPs and TIMPs in cigarette smoke-induced rat COPD model. Int J Chron Obstruct Pulmon Dis. 2017 Feb 22;12:717-724.

Uthus EO and Picklo MJ. Obesity reduces methionine sulphoxide reductase activity in visceral adipose tissue. Free Radic Res. 2011 Sep;45(9):1052-60.

Webster I, Salie R, Marais E, Fan WJ, Maarman G, Huisamen B, Lochner A. Myocardial susceptibility to ischaemia/reperfusion in obesity: a re-evaluation of the effects of age. BMC Physiol. 2017 Mar 17;17(1):3.

Wensley I, Salaveria K, Bulmer AC, Donner DG, du Toit EF. Myocardial Structure, Function, and Ischaemic Tolerance in a Rodent Model of Obesity with Insulin Resistance. In press. Exp Physiol. 2013 Nov;98(11):1552-64.

Yamada Y, Takeuchi S, Yoneda M, Ito S, Sano Y, Nagasawa K, Matsuura N, Uchinaka A, Murohara T, Nagata K. Atorvastatin reduces cardiac and adipose tissue inflammation in rats with metabolic syndrome. Int J Cardiol. 2017 May 4. pii: S0167-5273(16)32140-4. Ye Y, Martinez JD, Perez-Polo RJ, Lin Y, Uretsky BF, Birnbaum Y. The role of eNOS, iNOS, and NF-kappaB in upregulation and activation of cyclooxygenase- 2 and infarct size reduction by atorvastatin. Am J Physiol Heart Circ Physiol. 2008 Jul;295(1):H343-51 
Ye Y, Lin Y, Atar S, Huang MH, Perez-Polo JR, Uretsky BF, Birnbaum Y.Myocardial protection by pioglitazone, atorvastatin, and their combination: mechanisms and possible interactions. Am J Physiol Heart Circ Physiol. 2006 Sep;291(3):H1158-69.

Yoon D, Sheen SS, Lee S, Choi YJ, Park RW, Lim HS. Statins and risk for new-onset diabetes mellitus: A real-world cohort study using a clinical research database. Medicine (Baltimore). 2016 Nov;95(46):e5429.

Zhang Z, Tang L, Yu W, Chen Y, Dai YT. Improvement in erectile function in a rat model of high cholesterol diet-induced atherosclerosis by atorvastatin in a manner that is independent of its lipid-lowering property. Andrologia. 2017 Mar 10. doi: 10.1111/and.12789. [Epub ahead of print].

Zhao Q and Liao J. Statins and cardiovascular disease: from cholesterol lowering to pleiotropy. Curr Pharm Des 2009; 15(5):467-478.

Figure legends

Fig. 1. Body mass distribution in animals from the four groups as determined using DXA scans. Closed bars represent lean mass and open bars represent fat mass.

$\mathrm{n}=10-15$

$*<\mathrm{P}, 0.05$

Fig. 2. Homeostasis model assessment for insulin resistance (HOMA-IR) values for control and HCFD fed animals treated with vehicle or pravastatin.

$\mathrm{n}=6$

$*<\mathrm{P}, 0.05$ 
Fig. 3. Thiobarbituric Acid Reactive Substances (TBARS) levels in serum from the four groups of animals.

$\mathrm{n}=8$

$* \mathrm{P}<0.05$

Fig. 4. Myocardial infarct size as a percentage of the area at risk for control, HCFD, C+Prava and HCFD+Prava animals.

$\mathrm{n}=8-10$

* $\mathrm{P}<0.05$

Fig. 5 A and 5B. A. Myocardial glutathione peroxidase activity in hearts from control and HCFD fed animals treated with vehicle or pravastatin. B. Myocardial thioredoxin reductase activity in hearts from control and HCFD fed animals treated with vehicle or pravastatin. $\mathrm{n}=5$ $* \mathrm{P}<0.05$

Fig. 6A-F. Expression of proteins implicated in mitochondrial fission/fusion. A. Mitochondrial MFN-1 expression from control and HCFD fed animals treated with vehicle or pravastatin. B. Mitochondrial MFN-2 expression from control and HCFD fed animals treated with vehicle or pravastatin. C. Mitochondrial OPA-1 expression from control and HCFD fed animals treated with vehicle or pravastatin. D. Mitochondrial DRP-1 expression from control and HCFD fed animals treated with vehicle or pravastatin. E. Cytosolic DRP-1 expression 


\section{ACCEPTED MANUSCRIPT}

from control and HCFD fed animals treated with vehicle or pravastatin. F. Mitochondrial MFN-1:DRP-1 ratio in these hearts.

$n=4-6$

$* \mathrm{P}<0.05$

Fig. 7 A-F. Expression of pro- and anti-apoptitic proteins in the hearts of animals from the control, HCFD, C+Prava, HCFD and HCFD+Prava groups. A. Mitochondrial Bax expression, B. cytosolic Bax expression, C. mitochondrial Bcl-2 expression, D. Mitochondrial Bax:Bcl-2 ratio, E. total cytosolic caspase-3 expression and F. Cytosolic cleaved caspase -3 expression.

$n=4-6$

$* \mathrm{P}<0.05$

\section{Body Composition}

\section{Body Weight Visceral Fat Weight (Visceral Fat/Body \\ (g) \\ (g) \\ Weight)*100\%}

\begin{tabular}{llll}
\hline Groups & & & \\
C & $655 \pm 12$ & $40.6 \pm 3.1$ & $6.15 \pm 0.3$ \\
C+Prava & $616 \pm 17$ & $35.3 \pm 1.3$ & $5.70 \pm 0.2$ \\
HCFD & $736 \pm 15^{\mathrm{b}}(+12 \%)$ & $63.9 \pm 3.5^{\mathrm{c}}(+57 \%)$ & $8.64 \pm 0.4^{\mathrm{b}}(+40 \%)$ \\
HCFD+Prava & $696 \pm 11(+13 \%)^{*}$ & $58.8 \pm 3.5(+66 \%)$ & $8.42 \pm 0.4(+48 \%)$
\end{tabular}

Table 1. Body weight, visceral fat and visceral fat as a percentage of body weight for the four groups of animals after 16 weeks.

Value in brackets represent the \% change for the HCHF group compared to control group, and the $\mathrm{HCHF}+$ Prava group compared to the $\mathrm{C}+$ Prava group.

$\mathrm{n}=11-18$ 
${ }^{a} \mathrm{P}<0.05$ for HCFD vs. HCFD + Prava

${ }^{\mathrm{b}} \mathrm{P}<0.001$ for $\mathrm{C}$ vs HCFD

${ }^{c} \mathrm{P}<0.0001$ for $\mathrm{C}$ vs. HCFD

\begin{tabular}{llll}
\hline Groups & Total Cholesterol & Serum Lipid Levels & \\
& $(\mathbf{m m o l} / \mathbf{L})$ & HDL $(\mathbf{m m o l} / \mathbf{L})$ & $\begin{array}{l}\text { Triglycerides } \\
(\mathbf{m m o l} / \mathbf{L})\end{array}$ \\
\hline C & $>2.59$ & $0.78 \pm 0.07$ & $1.64 \pm 0.26$ \\
C + Prava & $>2.59$ & $0.98 \pm 0.18$ & $1.36 \pm 0.165$ \\
HCFD & $>2.59$ & $0.69 \pm 0.06$ & $2.91 \pm 0.52^{\mathrm{a}}$ \\
HCFD + Prava & $>2.59$ & $0.59 \pm 0.09$ & $1.68 \pm 0.12^{\mathrm{b}}$ \\
\hline
\end{tabular}

Table 2. Serum lipid levels of the four groups of animals after 16 weeks.

$n=5-7$

${ }^{\mathrm{a}} \mathrm{P}<0.05$ for $\mathrm{C}$ vs. HCFD

${ }^{\mathrm{b}} \mathrm{P}<0.05$ for HCFD vs. HCFD+Prava 


\section{ACCEPTED MANUSCRIPT}

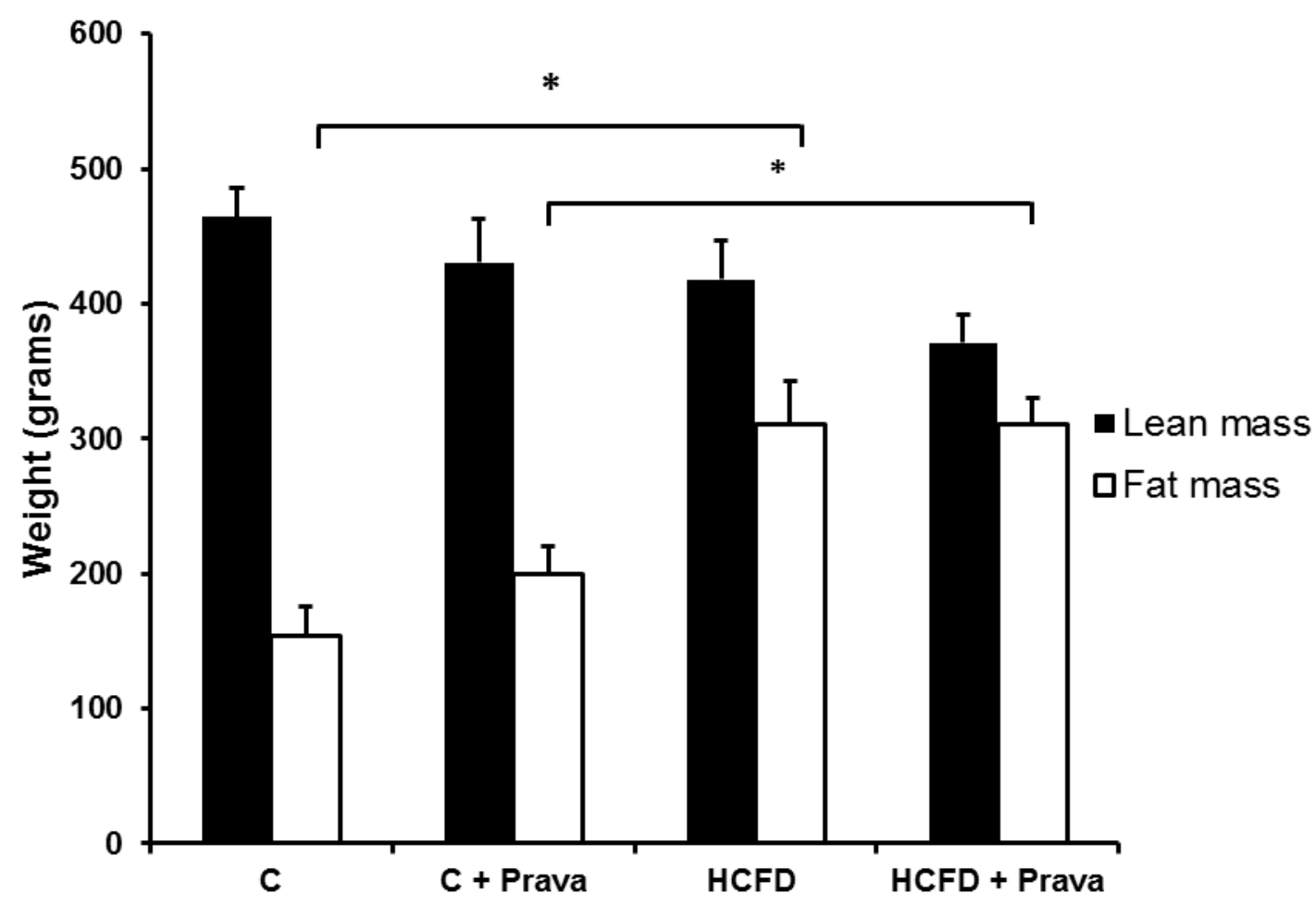

Fig 1. 

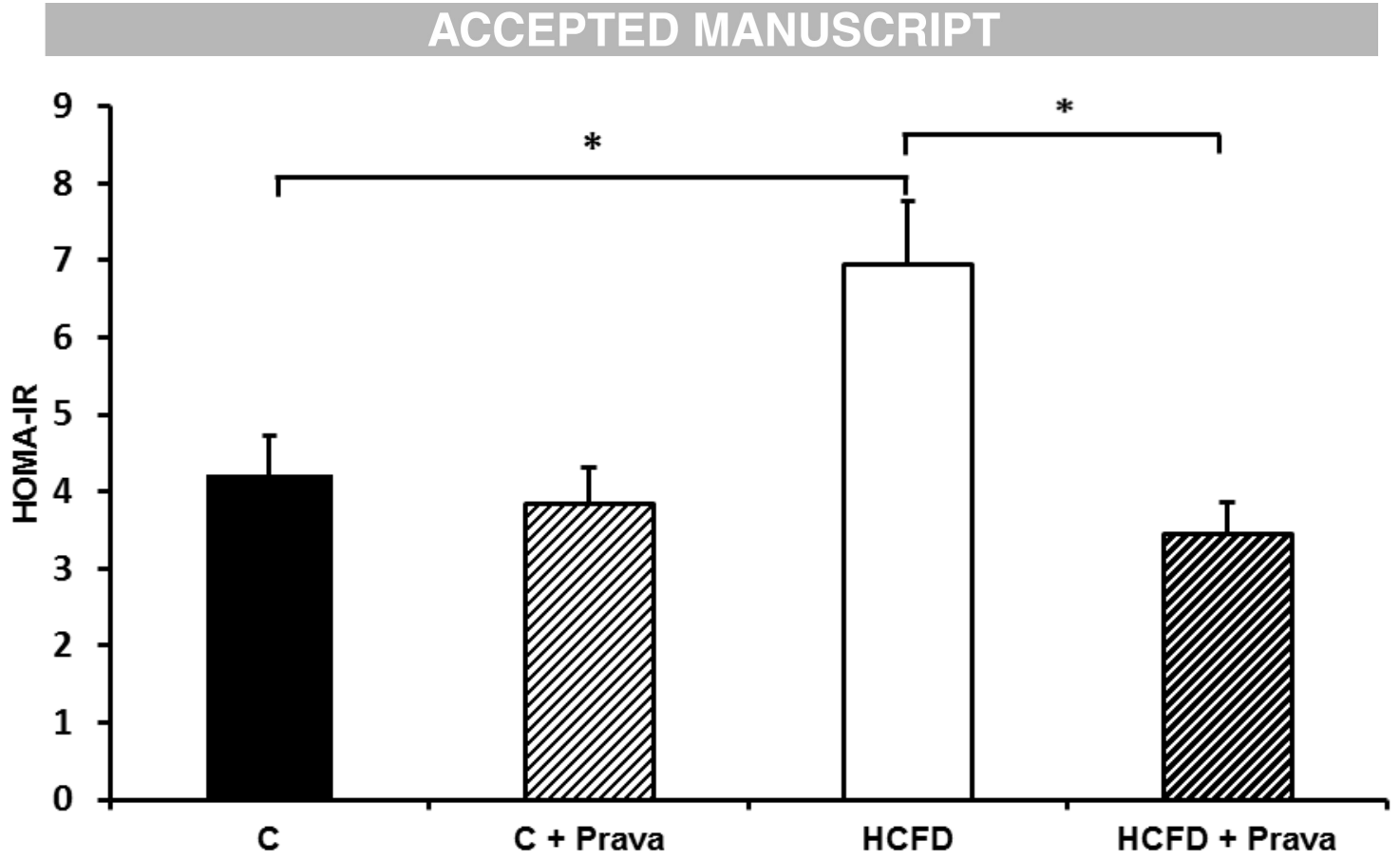

Fig 2. 


\section{ACCEPTED MANUSCRIPT}

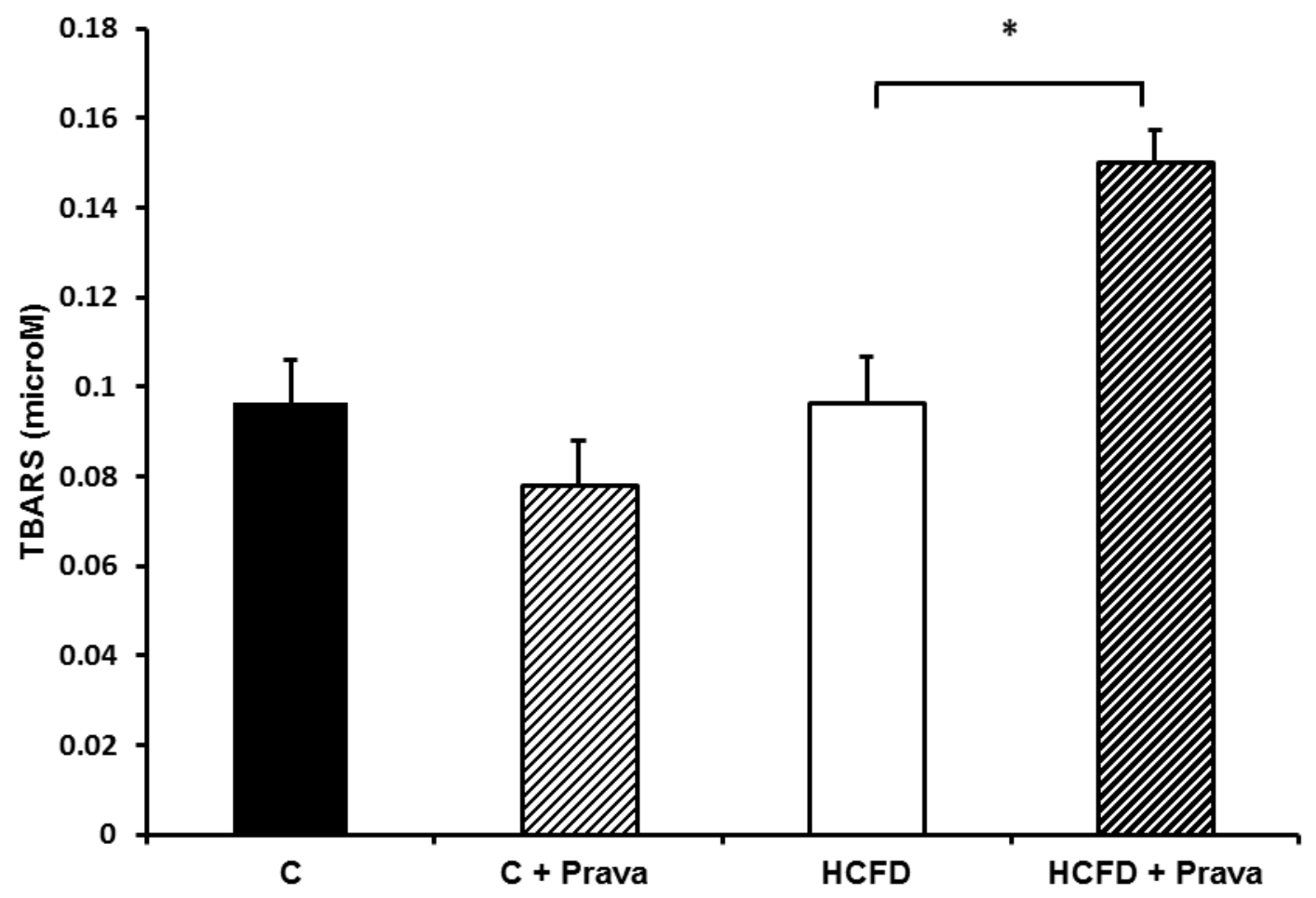

Fig 3. 


\section{ACCEPTED MANUSCRIPT}

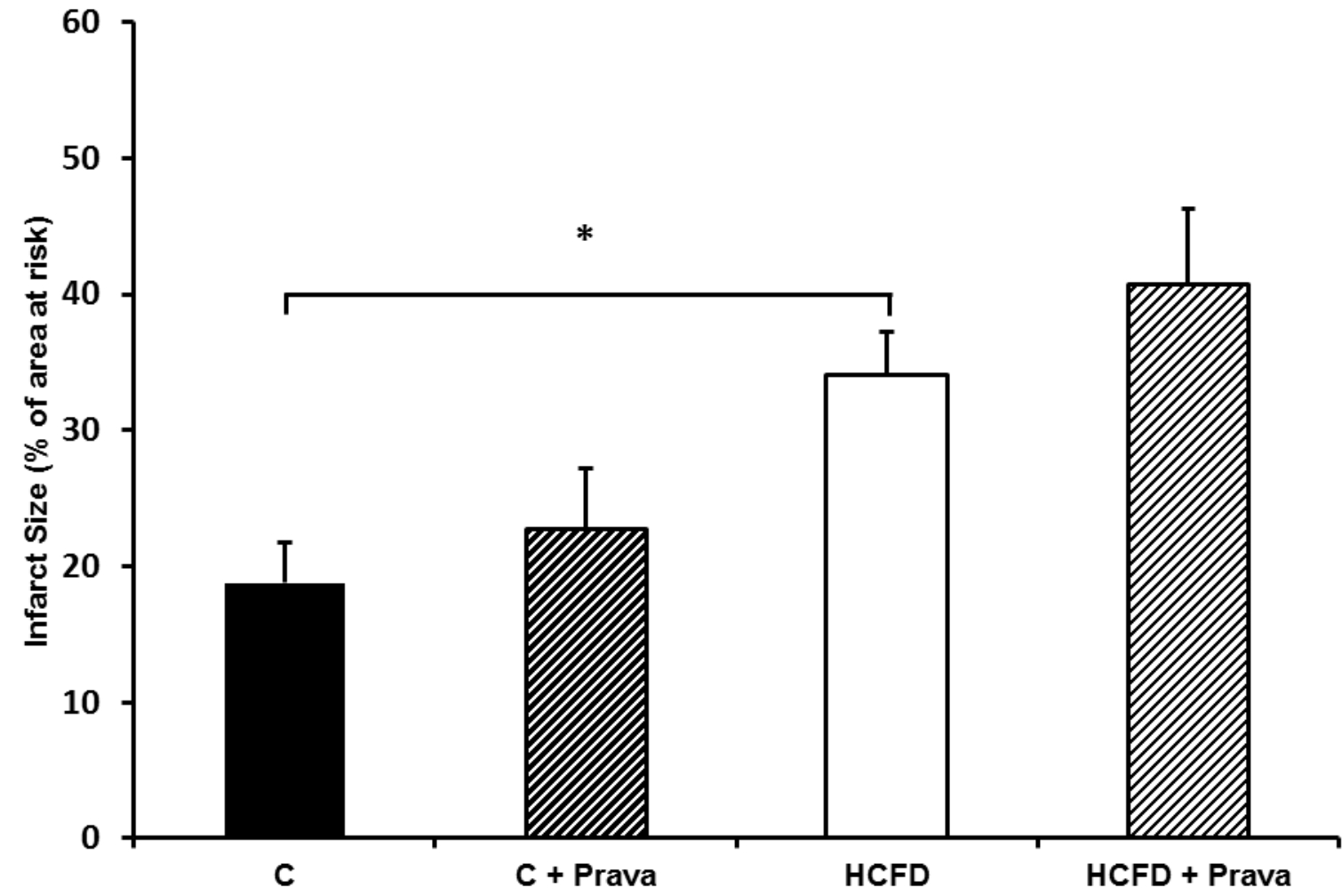

Fig 4. 
A

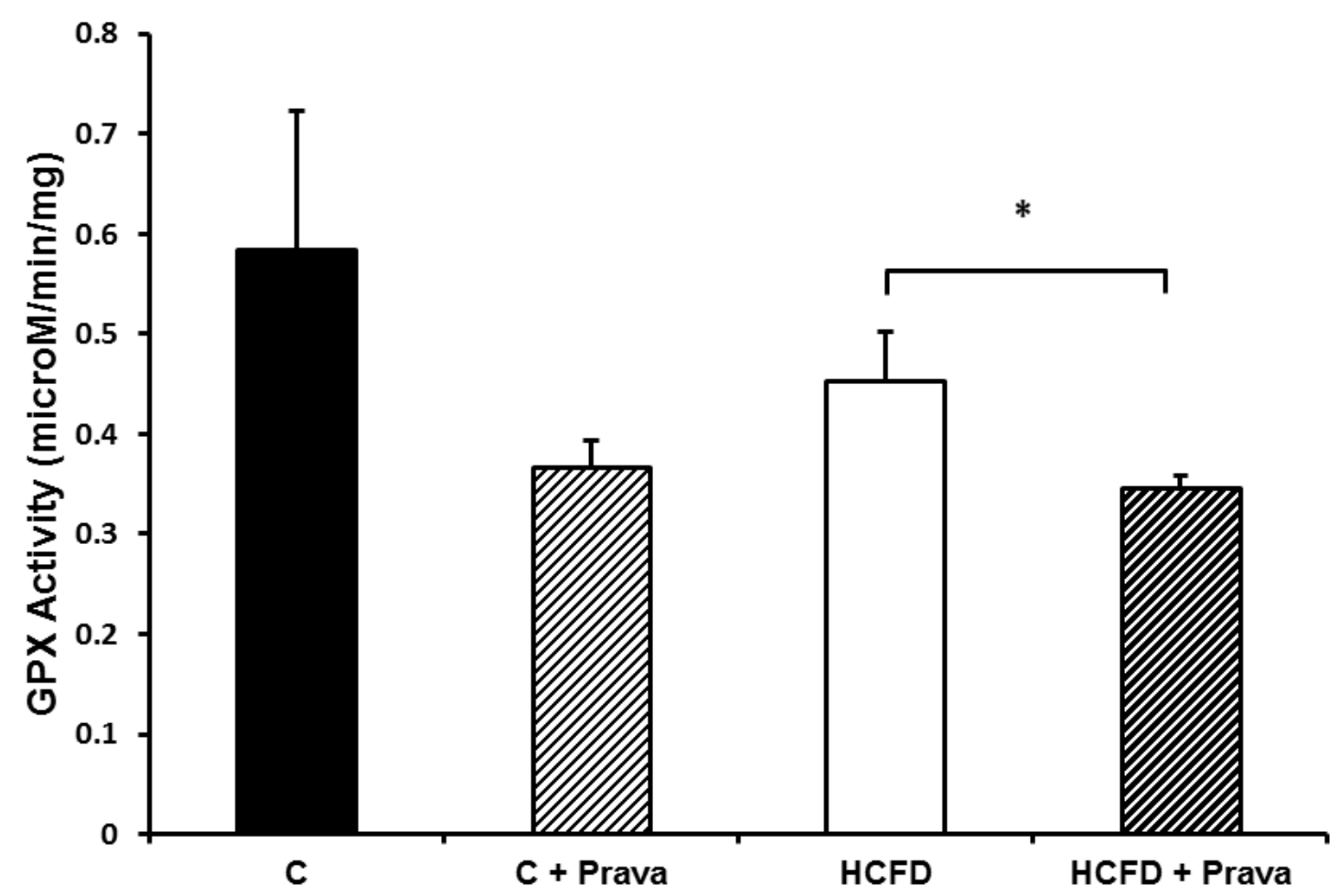

Fig 5 . 


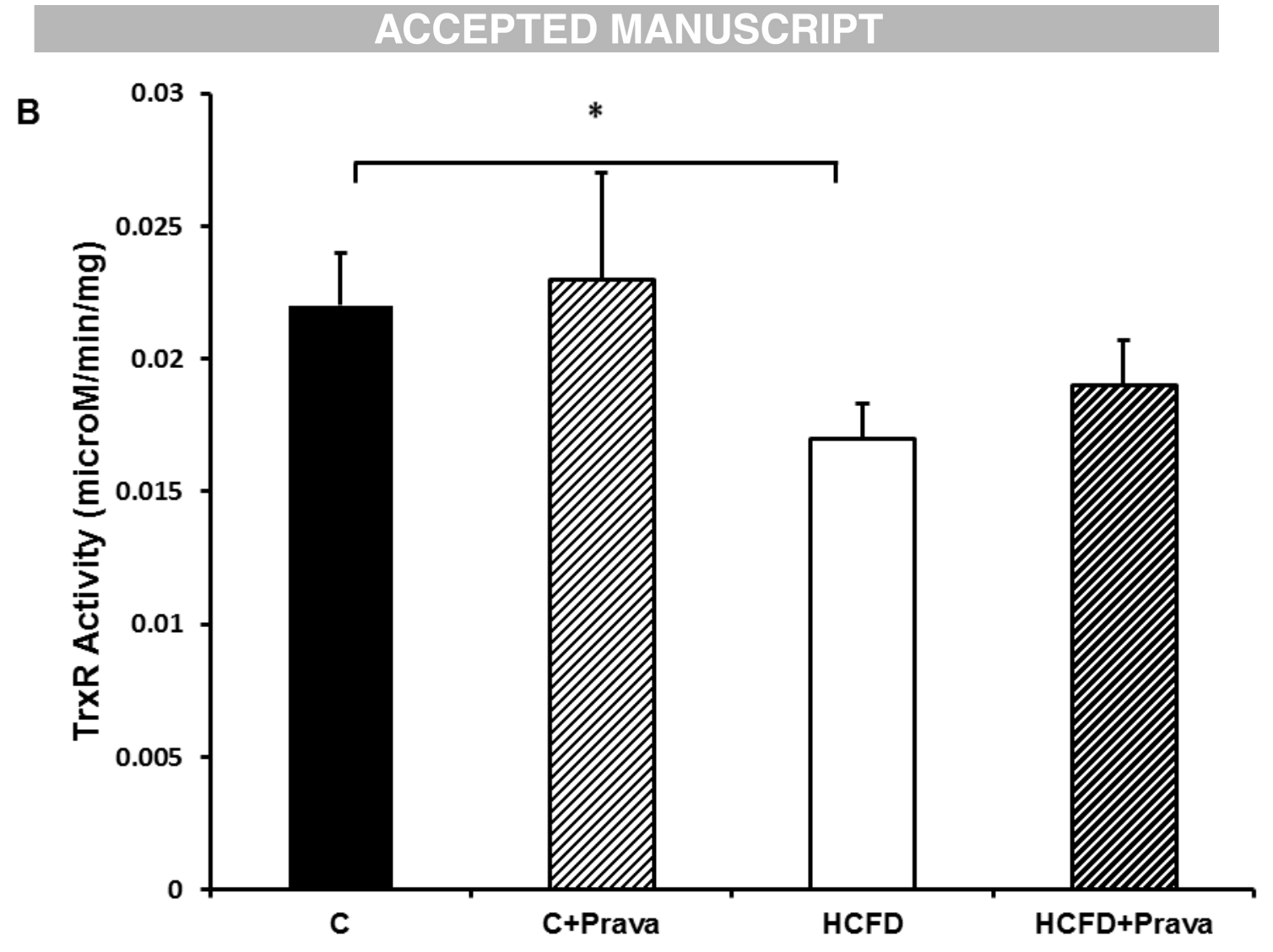

Fig 5. 


\section{ACCEPTED MANUSCRIPT}

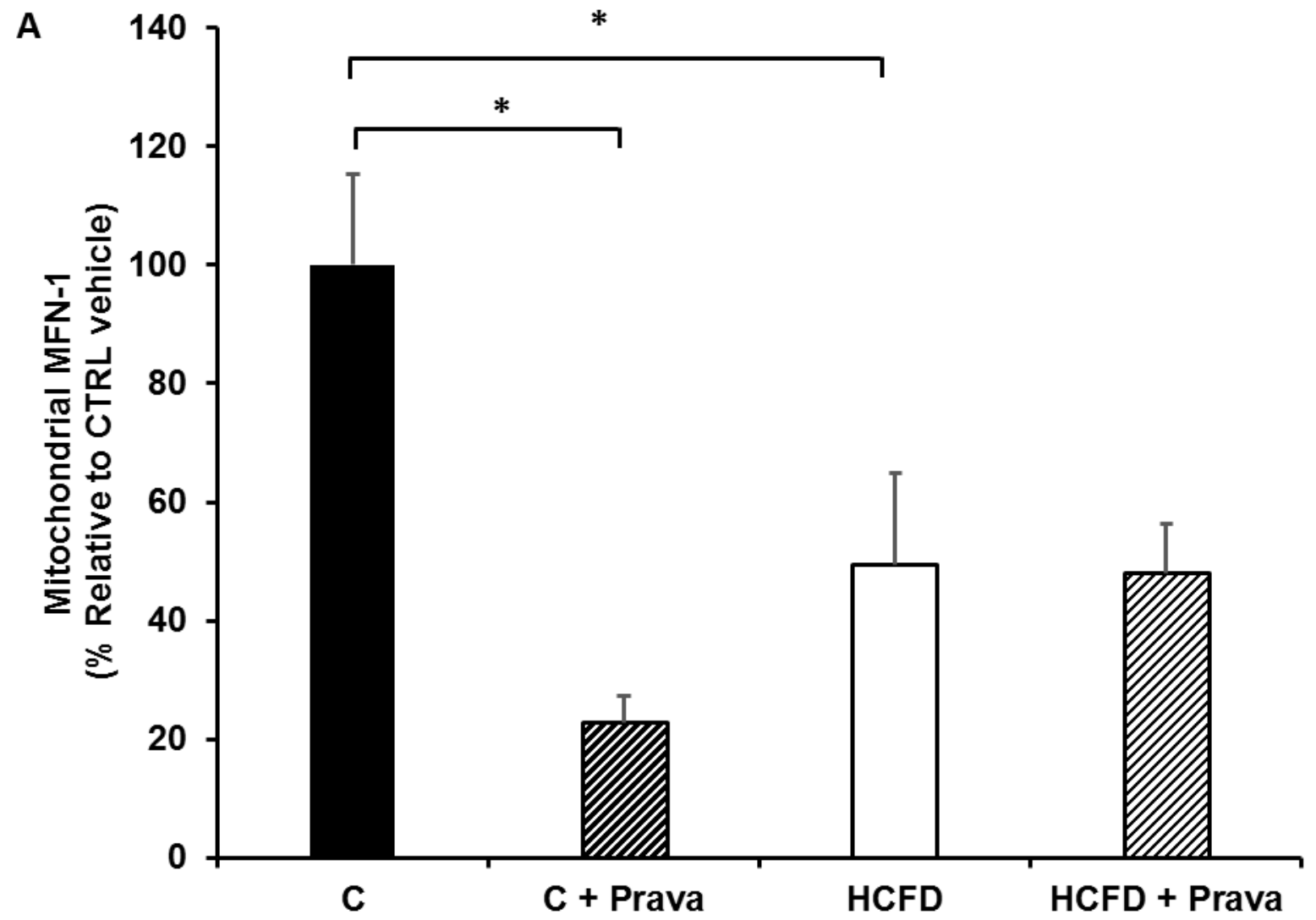

Fig 6. 


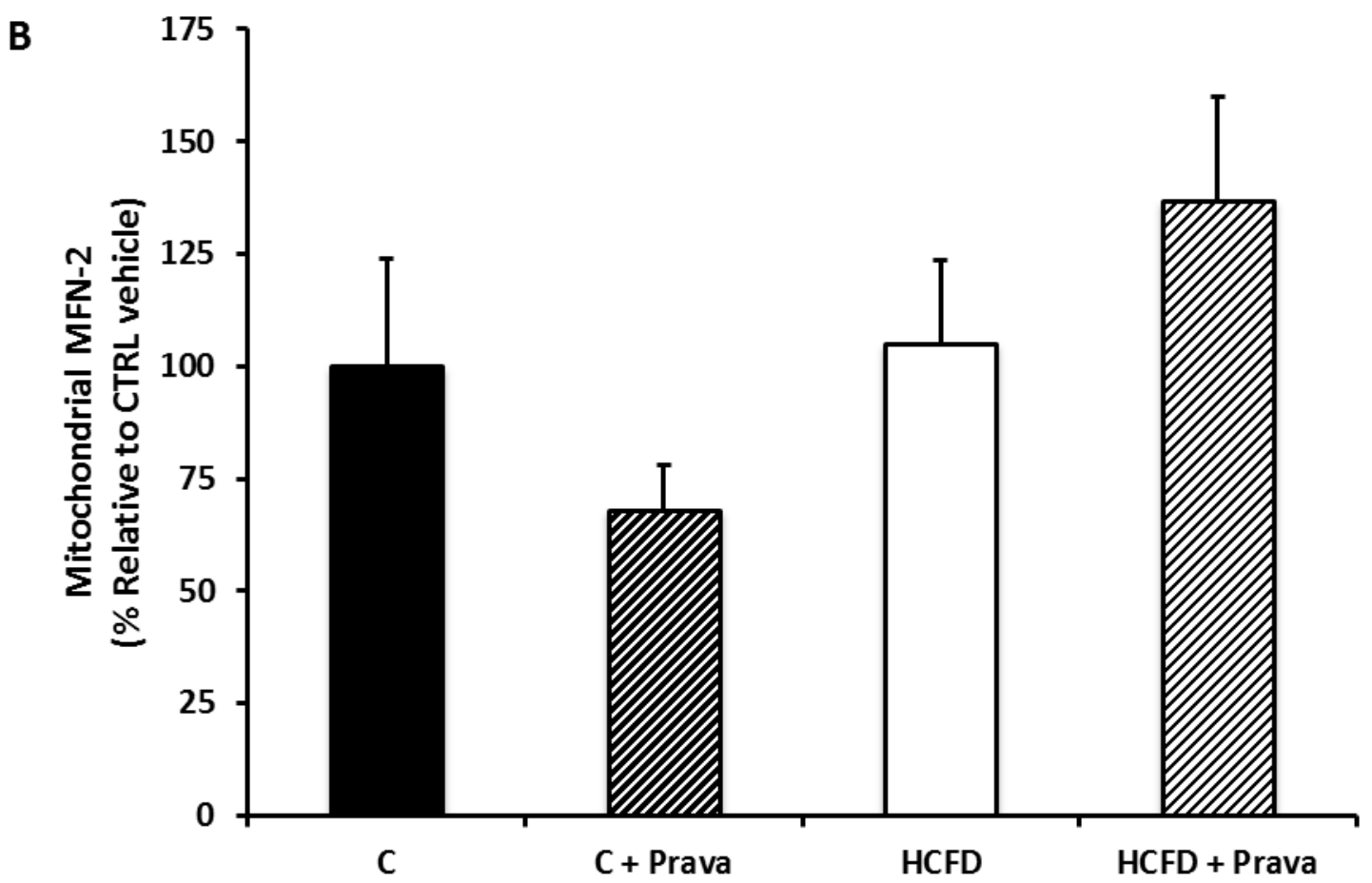

Fig 6. 


\section{ACCEPTED MANUSCRIPT}

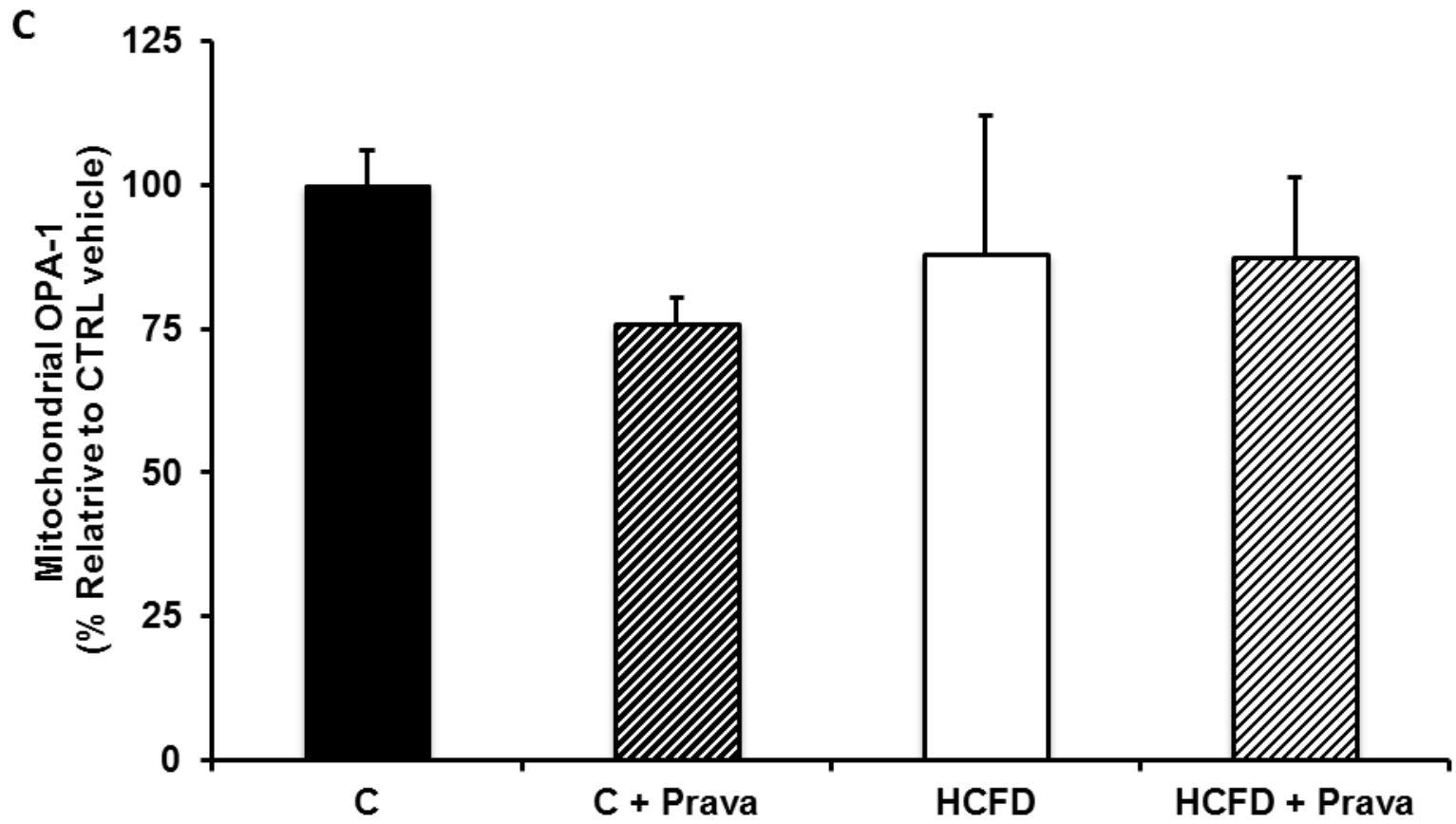

Fig 6. 


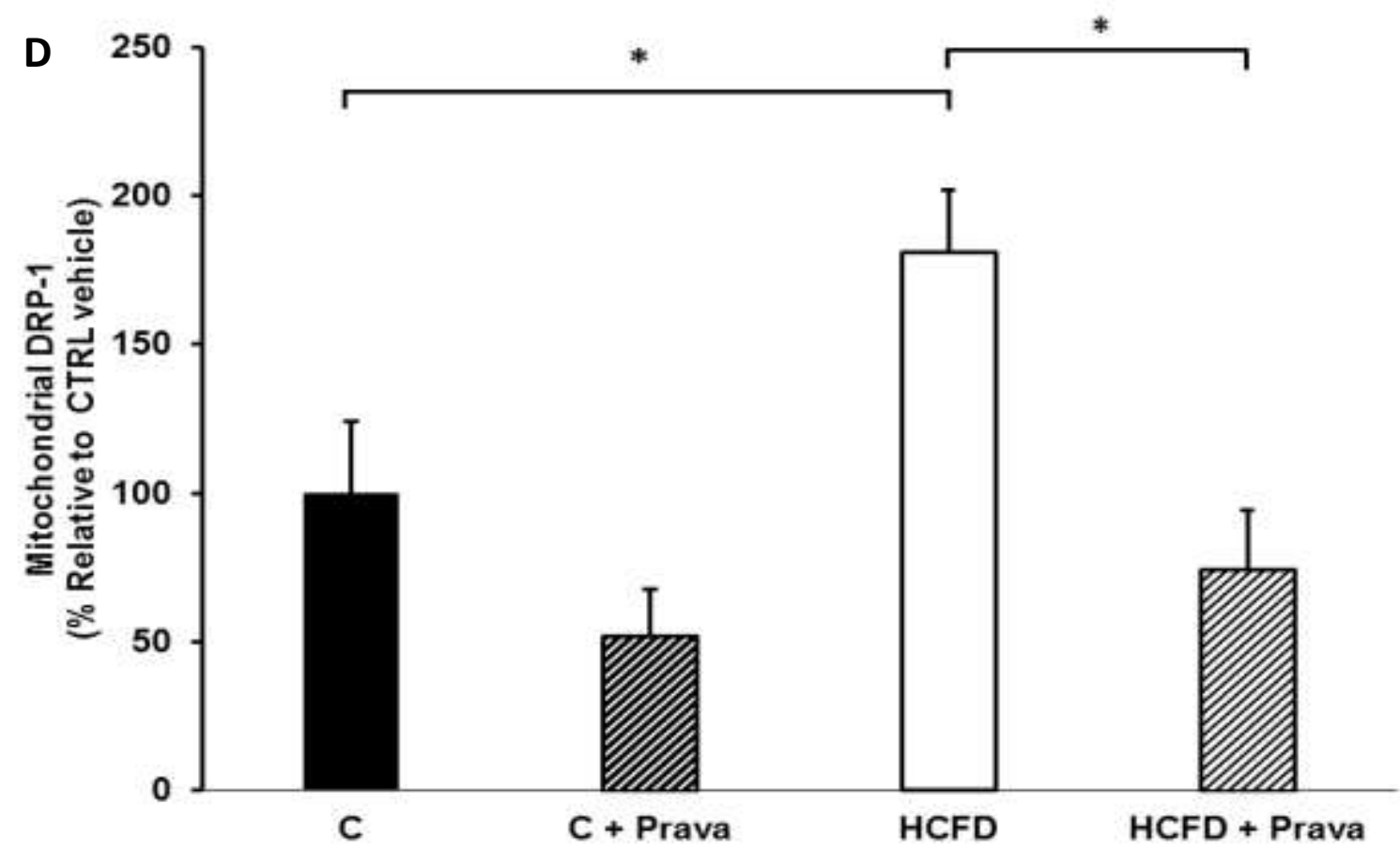

Fig 6. 
E

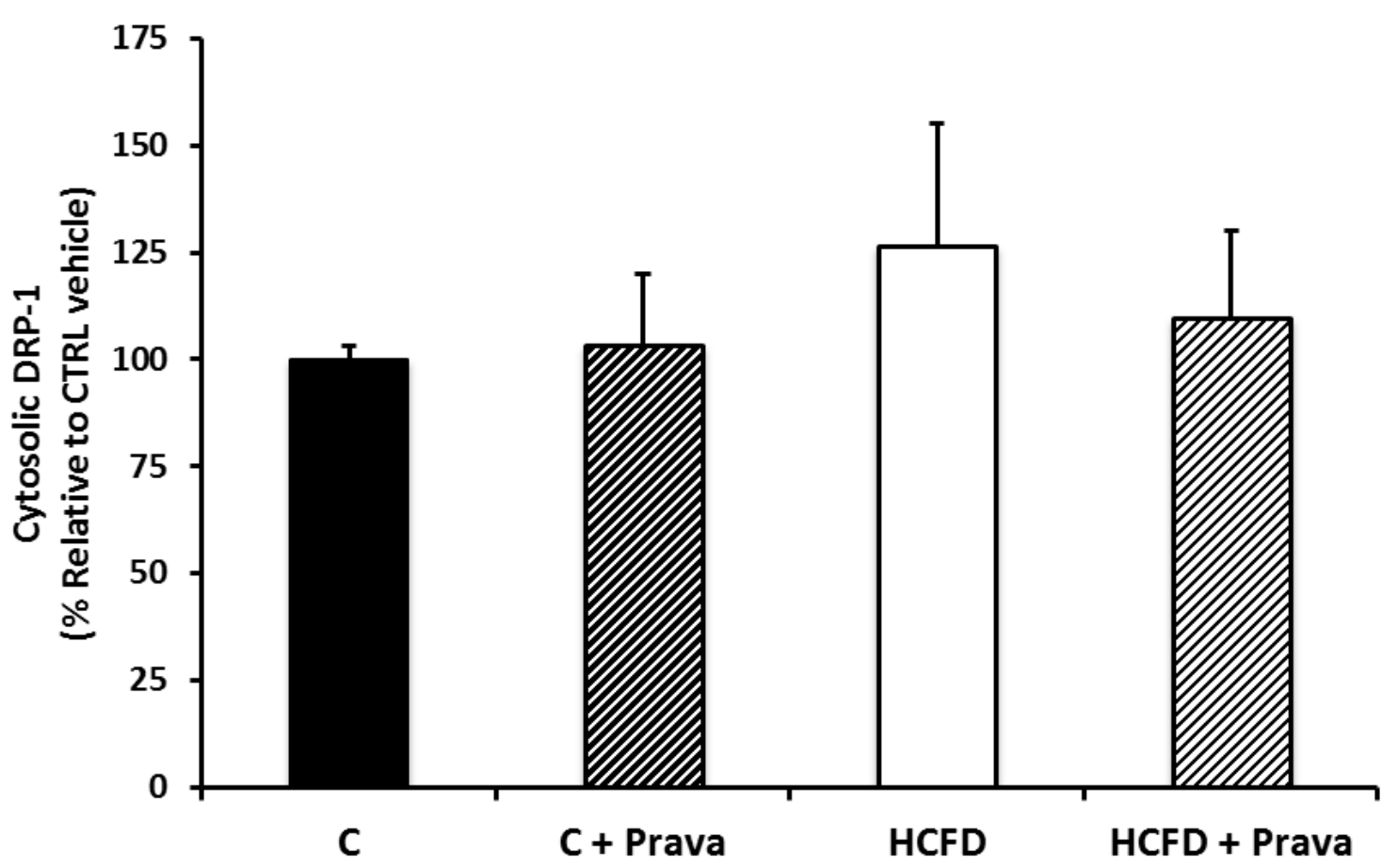

Fig 6. 


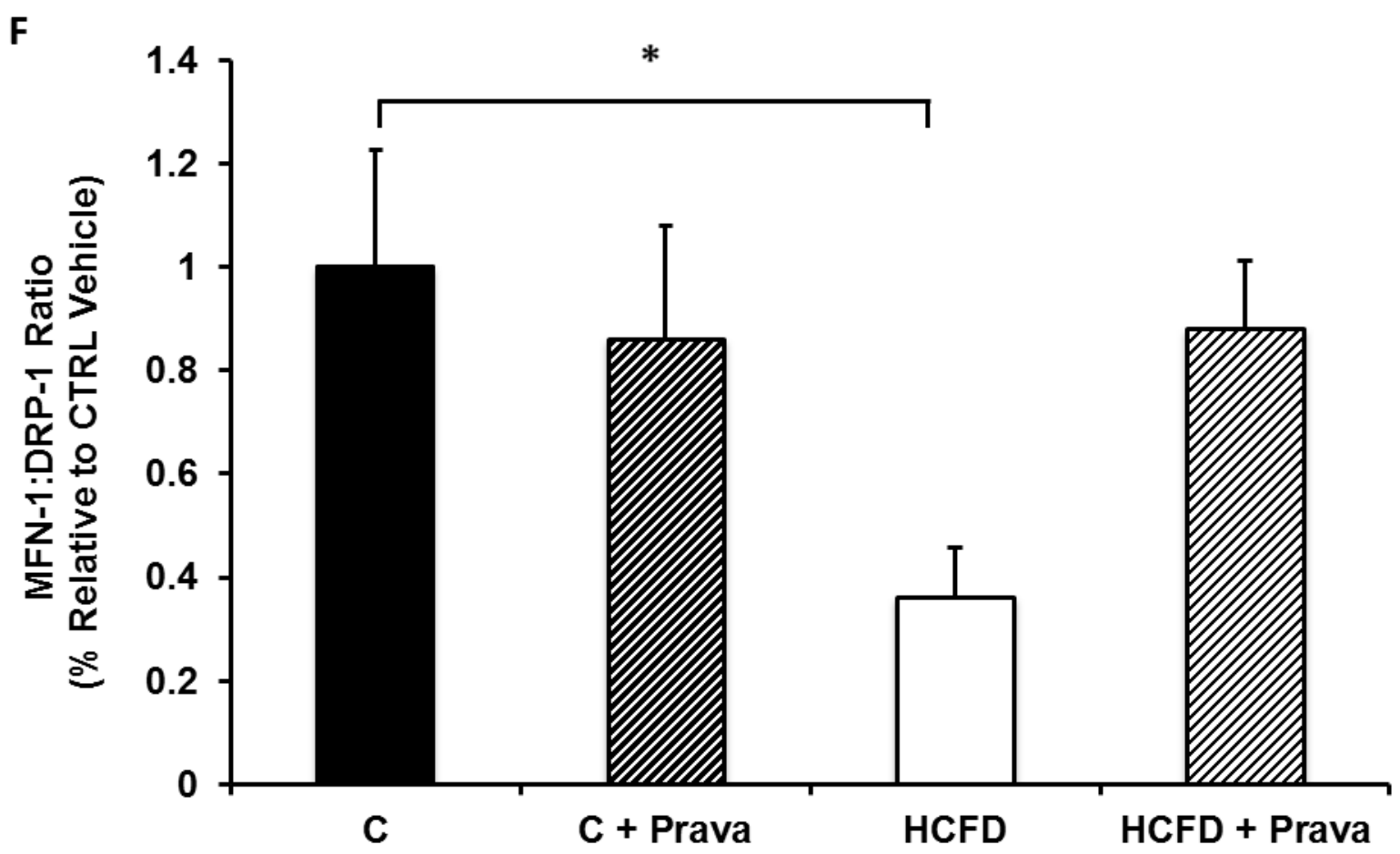

Fig 6. 


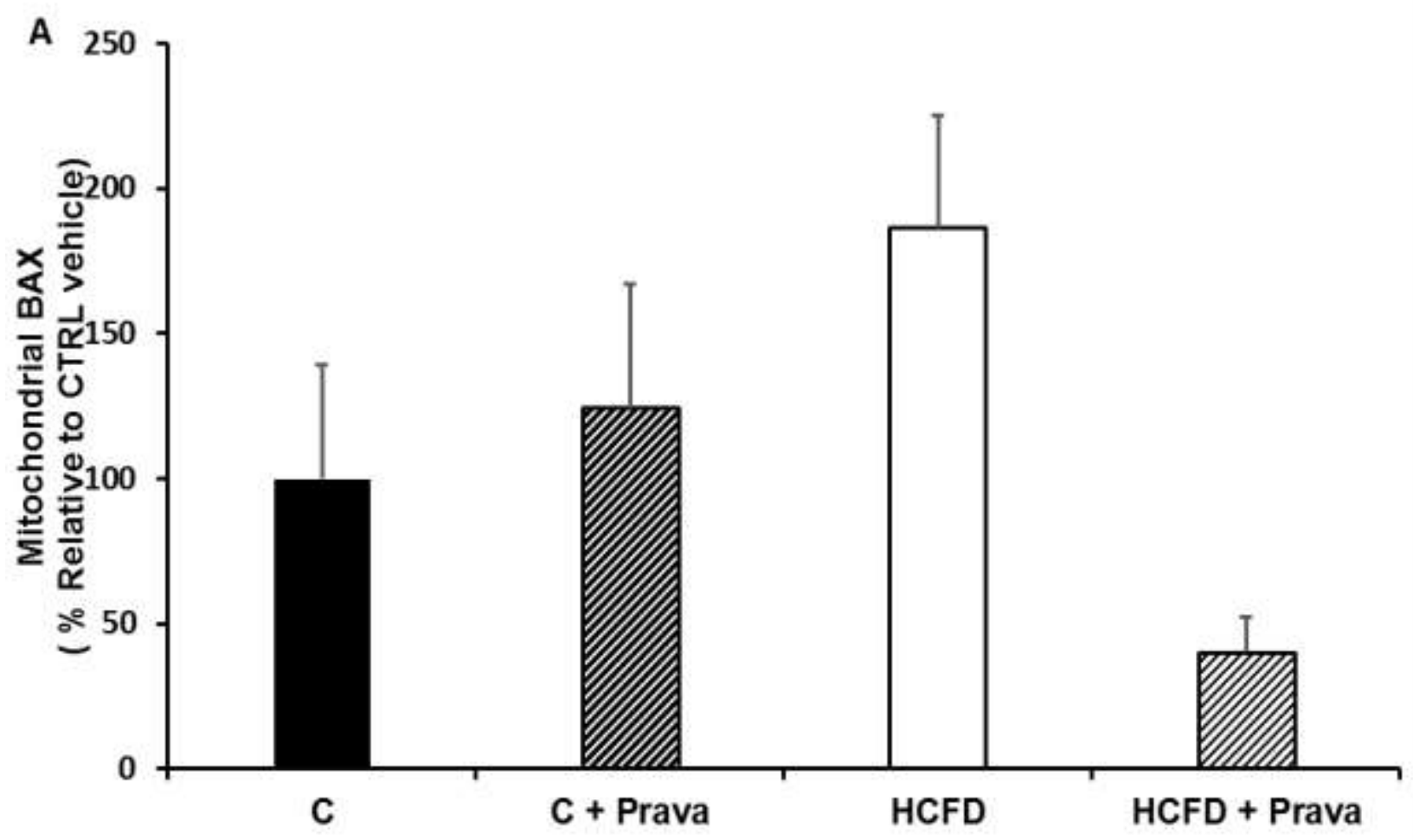

Fig 7. 
B

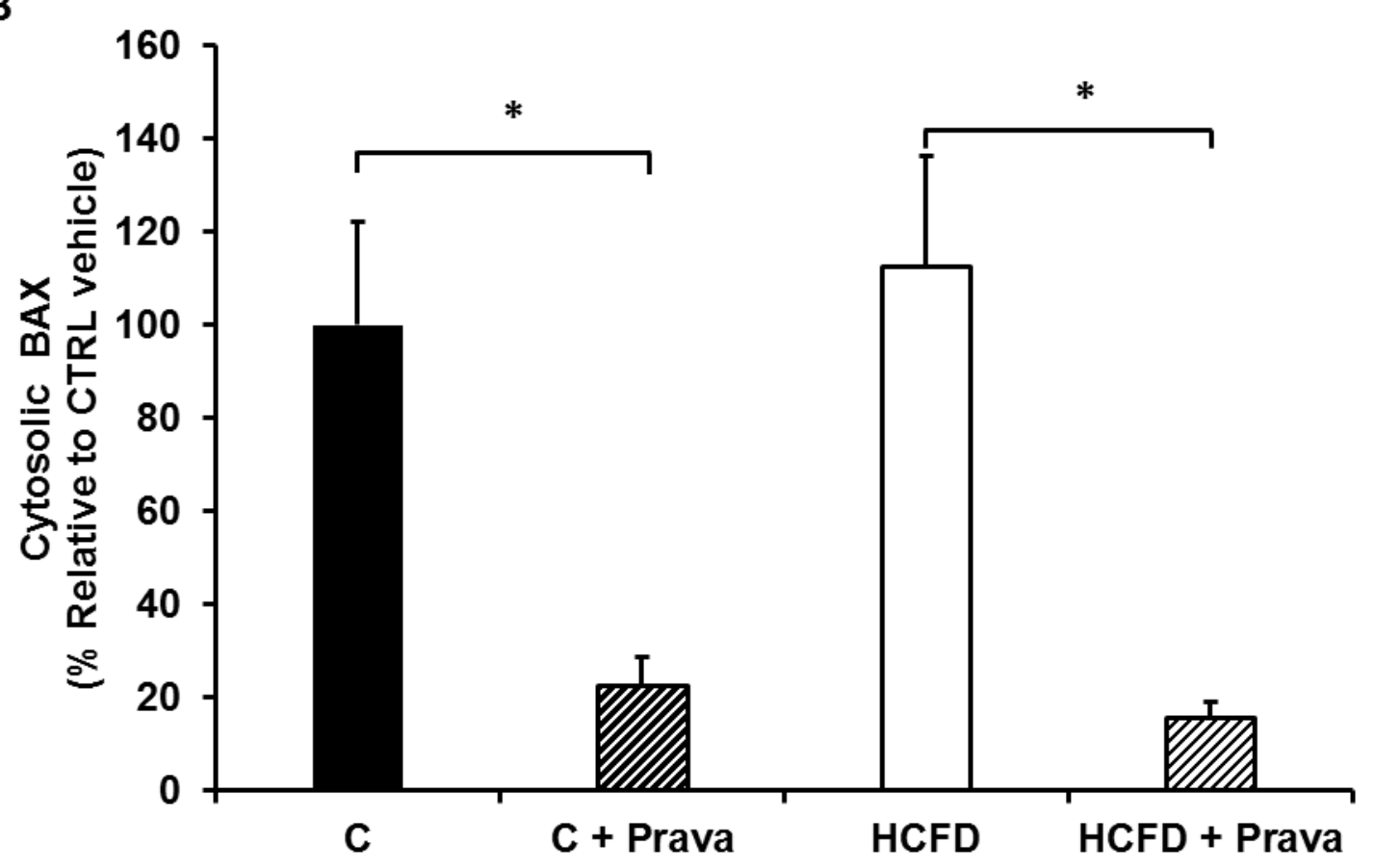

Fig 7. 


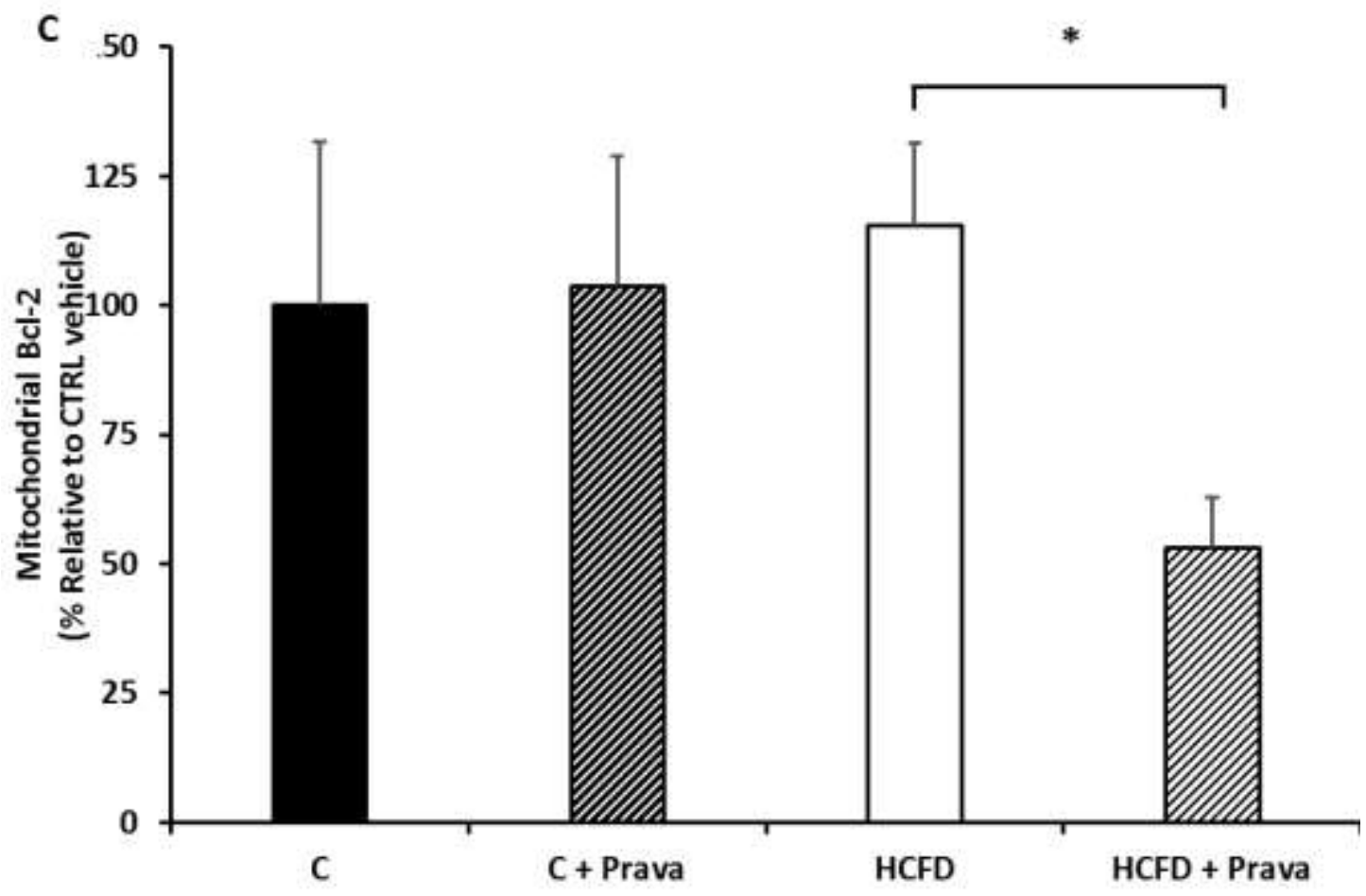

Fig 7. 


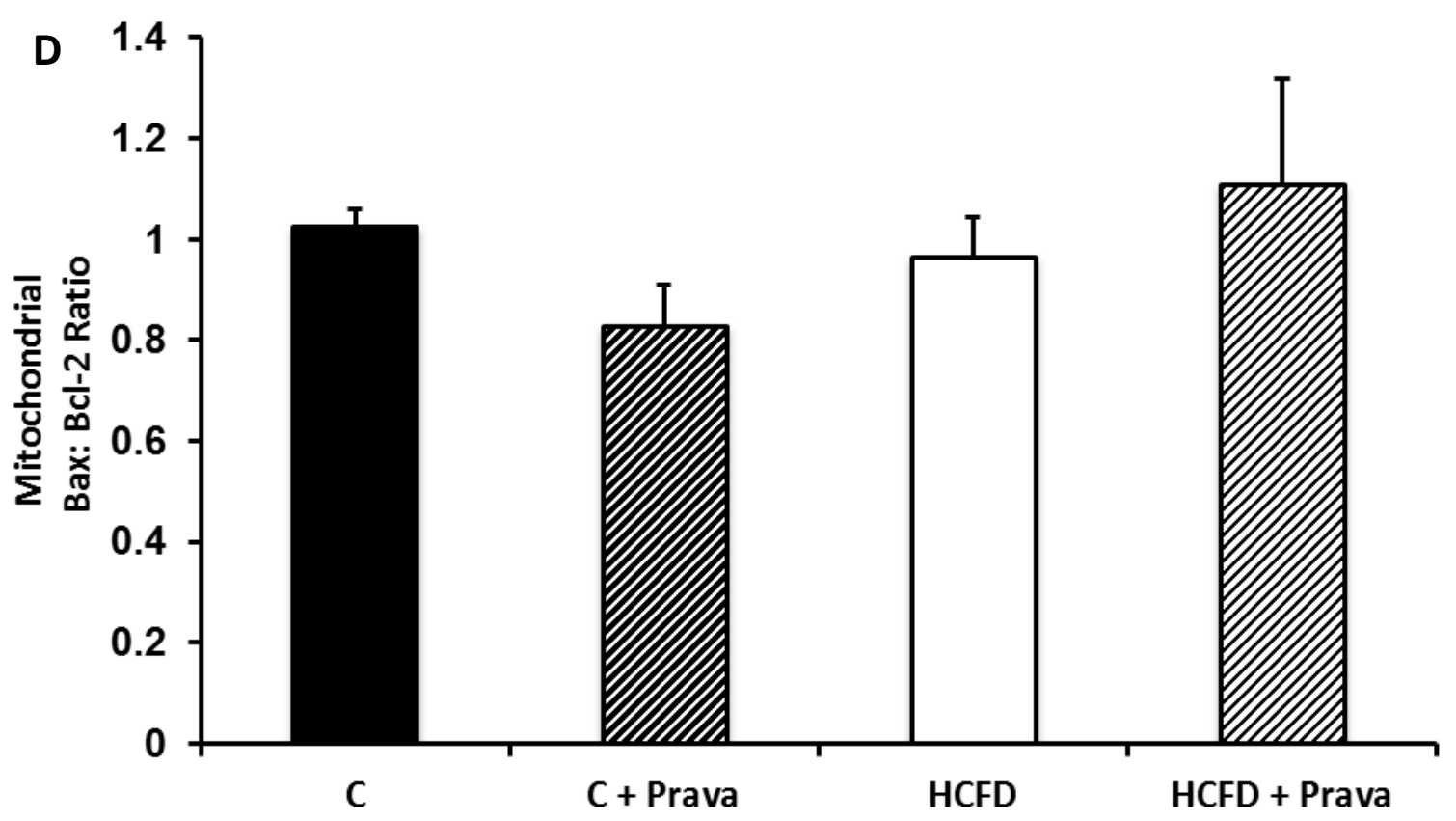

Fig 7. 


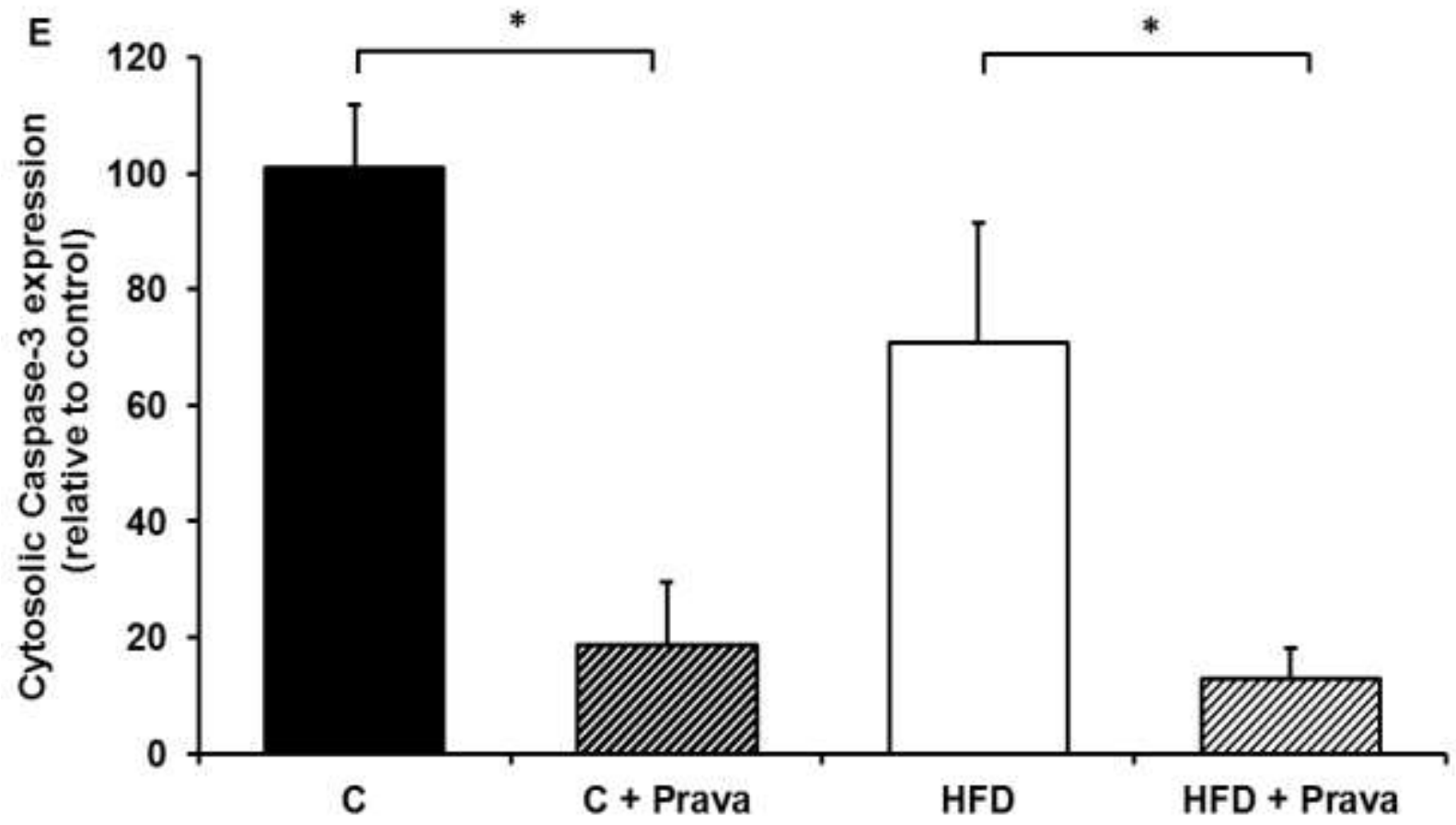

Fig 7. 


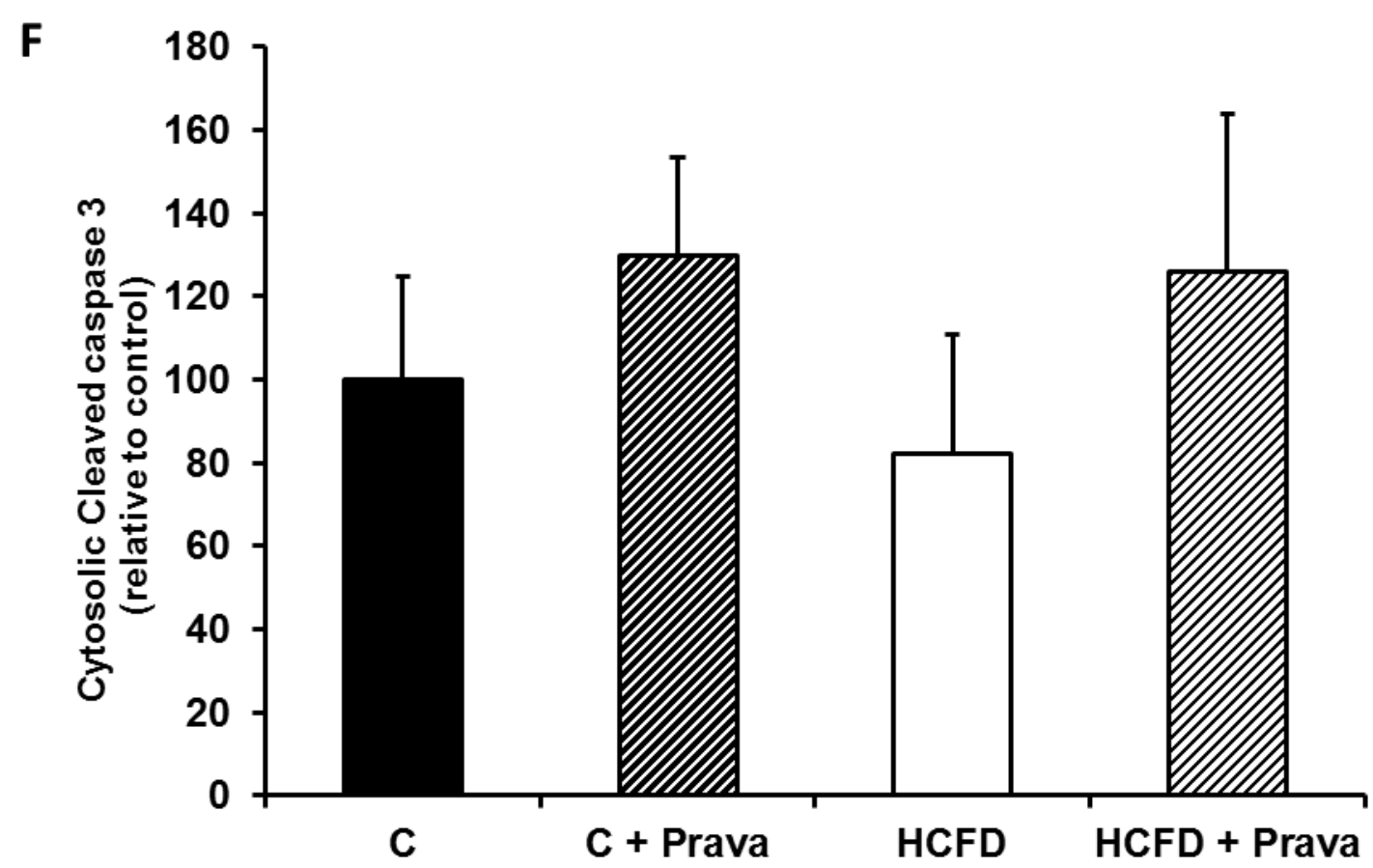

Fig 7. 


\section{Author's Accepted Manuscript}

Pravastatin improves risk factors but not ischaemic tolerance in obese rats

Massa Oi, Daniel Donner, Jason Peart, Belinda Beck, Lauren Wendt, John P. Headrick, Eugene F. du Toit

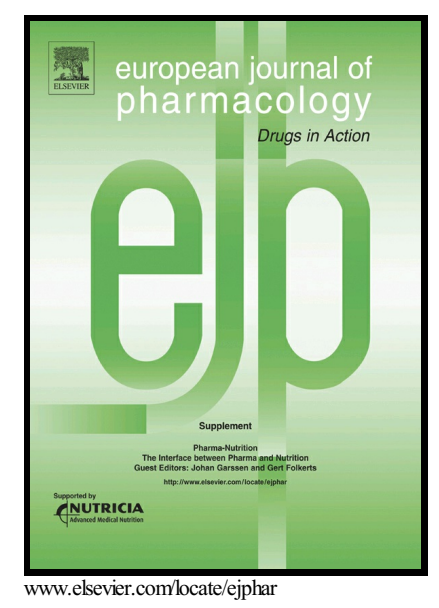

PII: $\quad$ S0014-2999(18)30136-5

DOI: $\quad$ https://doi.org/10.1016/j.ejphar.2018.02.050

Reference: EJP71703

To appear in: European Journal of Pharmacology

Received date: 31 August 2017

Revised date: 27 February 2018

Accepted date: 28 February 2018

Cite this article as: Massa Oi, Daniel Donner, Jason Peart, Belinda Beck, Lauren Wendt, John P. Headrick and Eugene F. du Toit, Pravastatin improves risk factors but not ischaemic tolerance in obese rats, European Journal of Pharmacology, https://doi.org/10.1016/j.ejphar.2018.02.050

This is a PDF file of an unedited manuscript that has been accepted for publication. As a service to our customers we are providing this early version of the manuscript. The manuscript will undergo copyediting, typesetting, and review of the resulting galley proof before it is published in its final citable form. Please note that during the production process errors may be discovered which could affect the content, and all legal disclaimers that apply to the journal pertain. 